\title{
Sistemas de riego en Ixmiquilpan, Tetepango y Tula, siglos XVII-XIX
}

\author{
Verenice Cipatli Ramírez Calva* \\ UNIVERSIDAD AUTÓNOMA DEL ESTADO DE HIDALGO
}

El presente artículo tiene como objetivo central analizar las pugnas y acuerdos por el uso, control y acceso al agua, surgidos entre elites regionales y pueblos de indios de las jurisdicciones de Tetepango, Ixmiquilpan y Tula en los siglos XVIII al XIX. Estos procesos claramente tienen sus raíces en la nueva conformación económica. Entre finales del siglo xviı y principios de la centuria siguiente, la economía regional viró hacia el cultivo de granos, pero sin dejar de lado la cría de ganado destinado a la arriería y la matanza. En ese contexto, las elites regionales invirtieron importantes capitales en la construcción de la infraestructura hidráulica necesaria para el riego de los cultivos de trigo. No obstante, desde siglos antes los pueblos de indios habían controlado gran parte de los recursos hídricos disponibles, por lo que la confrontación fue inevitable.

(Estado de Hidalgo, infraestructura hidráulica, virreinato, río Tula)

\section{Presentación}

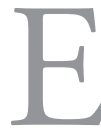

n las siguientes páginas analizaremos las formas en que pueblos de indios y hacendados de una amplia región -Ixmiquilpan, Tetepango y Tula- hicieron frente a la constante escasez de agua. Cronológicamente, nos ubicaremos en la segunda mitad del siglo XVII y principios del XIX, pues durante ese periodo se observan con mayor claridad no sólo las pugnas por el control y acceso al agua, sino también los mecanismos y acuerdos que se idearon para su uso.

Luego de un prolongado periodo en que la actividad principal de la región fue la ganadería, en las últimas décadas del siglo XVII y

*verenicecipatli@yahoo.com.mx 
principios de la siguiente centuria se detectó un marcado retorno a las prácticas agrícolas. Hasta ese momento los únicos que contaban con una infraestructura de irrigación eran los pueblos de indios; los antiguos ganaderos no la habían necesitado, pero al voltear cada vez más hacia la agricultura se dieron a la tarea de construirla. Igualmente este periodo se caracteriza por la constante preocupación por dar mantenimiento y revitalizar antiguas obras, sin con ello abandonar por completo la cría de ganado menor que distinguió a la región desde el siglo XVI. Las siguientes líneas tienen como principal preocupación mostrar las formas en que los pueblos, dueños de haciendas y molinos idearon una infraestructura hidráulica para su beneficio. No obstante que existía una legislación que normaba los usos del agua, lo cierto es que en muchas ocasiones los actores sociales involucrados tuvieron que llegar a acuerdos que no siempre eran permanentes o totalmente pacíficos, pero permitían acceder al vital líquido.

\section{Caracterización REgional}

Ixmiquilpan, Tetepango y Tula son actualmente municipios localizados al suroeste del actual estado de Hidalgo. Durante el virreinato cada uno de ellos fue cabecera de jurisdicción con varios pueblos sujetos, y a finales del siglo XvIII eran subdelegaciones pertenecientes a la intendencia de México. El espacio ocupado por las tres alcaldías mayores era un amplio territorio habitado por población nahua, otomí y pame.

Los valles de Tula, Ixmiquilpan y Tetepango se encuentran en la subcuenca del río Tula; ésta colinda al norte con la cuenca del Bajo Pánuco, al sur con la del Valle de México, al sureste con la del río Lerma y al poniente con la subcuenca del río San Juan del Río. En la región existen dos corrientes principales de régimen perenne que cruzan de sur a norte, el río Tula y El Salado. Originalmente, el primero nacía en el valle de Tula, pero desde la construcción del desagüe de la ciudad de México recibe agua de los ríos del valle de México y luego de entrar al actual estado de Hidalgo su caudal cruza por los municipios de Tula, Chilcuautla e Ixmiquilpan, para de ahí continuar su curso al noroeste hasta unirse a los ríos Moctezuma y Pánuco, y fi- 
nalmente desembocar en el Golfo de México. Asimismo, durante su curso, el río Tula se alimenta del caudal de otros como el Tepexi, El Salto y Rosas. El segundo río en importancia en la región es El Salado; se origina en el cerro El Epazote con el nombre de arroyo Tenguendó, en las inmediaciones de Hueypuchtla, y al llegar al túnel de Tequixquiac cambia al de río Salado; y ya en las cercanías de los municipios de Mixquiahuala y Tezontepec se une al Tula. ${ }^{1}$ En torno a estos cinco ríos se encontraban las tierras más fértiles de la región, y de ellos se alimentaban los principales sistemas hidráulicos.

A pesar de contar con ríos de caudal considerable, Ixmiquilpan y Tetepango, al igual que los pueblos de sus contornos, son caracterizados en las fuentes históricas como zonas semiáridas donde abundan mezquites, nopales, magueyes y cardos. Desde siempre han sido lugares sujetos a frecuentes heladas y granizo; mientras que las precipitaciones pluviales son, por lo general, escasas. ${ }^{2}$ A principios del siglo XIX, Juan Nepomuceno Bretón, subdelegado de Tetepango, describía el clima y suelo de la jurisdicción a su cargo como: "árido, tepetatoso o arcilloso, sujeto a las aguas temporales; y se cogen éstas en jagüeyes o tazas que se disponen en la misma tierra para el sustento de gentes y animales [...] Todo este país está cubierto de espinas y abrojos, que producen magueyes, cardones, cambrones y biznagas y otros arbustos". ${ }^{3}$ Años antes, Villaseñor y Sánchez indicaba que Atitalaquia era uno de los pueblos de esa jurisdicción donde las lluvias podían ser más abundantes:

experimentase su temperamento igual al de su capital, y aunque como ella padece escasez de aguas, se muestran las nubes más benignas en su territorio, cuyos campos se registran acompañados de varias haciendas y ranche-

${ }^{1}$ Laura Elena Maderey, "El recurso agua en la República Mexicana. Un breve análisis geográfico”, Revista Geográfica, Pan American Institute of Geography and History, núm. 119, enero-junio, 1994, 141.

${ }^{2}$ Felipe I. Echenique March y Lourdes M. Romero Navarrete, Relaciones geográficas de 1791, México, INAH, 1994, 92, 112; Antonio Alcedo, Diccionario geográfico-histórico de las Indias Occidentales, tomo v, Madrid, Imprenta de Manuel González, 1789, 105.

3 "Carta de Nepomuceno Bretón, subdelegado de Tetepango (1801)", AGN, Indiferente Virreinal, caja 3521, exp. 1, f. 1v. 
rías de labor, donde se logran las cosechas de trigo, maíz y demás semillas que siembran. ${ }^{4}$

\section{En Ixmiquilpan la falta de agua también era una constante:}

Su temperamento es caliente y seco, sin embargo de experimentarse en él el extremo de que en el estío son excesivos los calores y en el invierno intolerables los fríos; padece escasez de aguas, por lo que carece de fertilidad el territorio $[\ldots]$ y el comercio de unos y otros se reduce a la fábrica de jarcia, hilados, tejidos de algodón, mieses, frutas y crías de ganado menor, y aunque hacen sus siembras, son moderadas las cosechas de las semillas que logran, por la carencia de las aguas. ${ }^{5}$

Los pueblos sujetos a la parcialidad de Tlazintla, al sur y sureste de Ixmiquilpan, eran mucho más fértiles, pues algunas de sus tierras eran bañadas por las aguas del río Tula y el arroyo Tecolote:

su temperamento es benignamente templado con el beneficio de fertilizarlo las aguas de un caudaloso río, que desciende de la Sierra de Mextitlán [sic], haciendo círculo a los barrios de su circunferencia, por lo que es muy ameno el país, y abundante de frutas y hortalizas, a cuyo trato agregan las porciones de carbón, que hacen en un cerro contiguo a la cabecera; siembran sus semillas, aunque en corta cantidad. ${ }^{6}$

En cambio, Tula es descrito con características muy diferentes. Villaseńor, por ejemplo, indica que "el pueblo principal como sus barrios son de fértil terreno, y temperamento benigno, llevando

${ }^{4}$ Antonio Villaseñor y Sánchez, Teatro americano, descripción general de los reinos y provincias de la Nueva España y sus jurisdicciones, México, Editora Nacional, 1951-1952, 146.

${ }^{5}$ Ibidem, p. 151.

${ }^{6}$ Ibidem, p. 152. Villaseñor señala que el río que rodea los pueblos de Tlazintla desciende de Meztitlán. Posiblemente se trate del río Tula que corre del lado oeste de Tlazintla. El problema es que no desciende de Meztitlán sino del Valle de México. También es probable que haga referencia al arroyo Tecolote o el Chilcuautla que atraviesan de sur a norte por las tierras de esa parcialidad, pero éste tampoco viene de aquel lugar (Instituto Nacional de Estadística, Geografía e Informática, Carta Topográfica 1: 50000, Ixmiquilpan F14C79). 
muchas frutas, y pingües sementeras todas las labores de su distrito"; y añade, "a más de ser muy fértil, y abundante de aguas, lleva crecidos frutos". ${ }^{7}$ El Padrón de la jurisdicción de Tula de 1792 va por el mismo tenor. A pesar de que el terreno presenta una topografía irregular se considera bueno para el cultivo: "su terreno, aunque montuoso y desigualísimo es excelente; se coge maíz, trigo en abundancia y sobre todo fruta exquisita de ambas tierra fría y caliente". Lo mismo se decía de uno de sus sujetos, Tepeji del Río, asentado en las márgenes del río del mismo nombre: "este pueblo es bastante gracioso sobre todo muy agradable por la fertilidad de sus campos y cańada llena de huertas y frutas ricas de todas especies". 8

A pesar de la conocida aridez del medio se lograban cosechar semillas, legumbres y frutas gracias a la construcción de canales, jagüeyes y presas. ${ }^{9}$ Es posible que el riego haya estado presente en la región desde al menos el periodo Clásico. Los estudios arqueológicos de la antigua ciudad de Tula han detectado que durante el Clásico Temprano (300-750 d. C.) el sitio de Chingú, en las inmediaciones del municipio de Tlaxcoapan, funcionó como centro provincial de Teotihuacán. Un aspecto relevante del lugar es que está rodeado de tierras irrigadas a través de sistemas hidráulicos, que los arqueólogos consideran precolombinos, pues los asentamientos de ese periodo se localizaban justo a las orillas de canales. Es posible que durante el Posclásico Temprano un grupo de especialistas asentados en zonas rurales fueran los administradores y constructores de extensos sistemas de riego en los valles aluviales al oeste, norte y sur de Tula; esos sistemas llegan a medir varios kilómetros de largo. Mastache y Cobean consideran que los sistemas de riego y las zonas de explotación de cal fueron la

${ }^{7}$ Antonio Villaseńor y Sánchez, op. cit., p. 89.

8 "Padrón de la jurisdicción de Tula (1792)", AGN, Padrones, vol. 7, fs. 297r-297v.

${ }^{9}$ AGN, Tributos, vol. 55, exp. 4, f. 215r; "Relación que manifiestan los temporales y cosechas de la jurisdicción de Tetepango en los primeros seis meses de este ańo de 1809", AGN, Indiferente Virreinal, caja 5784, exp. 29, f. 1r; "Cosechas y temporales de los seis meses segundos de '93 (1793)”, AGN, Indiferente Virreinal, caja 3346, exp. 9, f. 30r; "Relación de los temporales y cosechas de la jurisdicción en el segundo semestre de 1808”, AGN, Indiferente Virreinal, caja 3497, exp. 17, f. 2r; AGN, Indiferente Virreinal, caja 5024, exp. 18, f. 3 r. 
clave económica del éxito del Estado tolteca. ${ }^{10}$ De acuerdo con Brigitte Boehm de Lameiras, en las últimas fases toltecas los mexitin construyeron presas y canales en la región. A través de un recorrido de superficie, Guadalupe Mastache considera que muchos de los canales de riego en las inmediaciones de los pueblos y de las antiguas haciendas eran de origen precolombino, sin embargo, gracias a un estudio de fuentes novohispanas sólo pudo rastrearlos hasta el siglo XVIII. ${ }^{11} \mathrm{La}$ evidencia arqueológica con la que hasta el momento se cuenta en la región requiere de un análisis más profundo y exhaustivo que nos permita conocer más ampliamente los sistemas de riego.

La Suma de visitas proporciona informes de pueblos que a principios del en el siglo Xvi tenían acequias y jagüeyes destinados al cultivo o al beneficio doméstico. Por lo general, los pueblos cercanos a ríos o arroyos derivaban las obras hidráulicas de éstos; por ejemplo, del río Tula se regaban las tierras de Tula y sus sujetos: Atengo, Nextlalpan y Tepetitlán. Río abajo se beneficiaban del agua Ixmiquilpan, Tlacotlapilco, Tezontepec (hoy Tezontepec de Aldama) y Chilcuautla. Mientras que los sujetos a Tetepango sangraban el río Salado para llevar agua a sus cultivos; en ese caso se citan Atitalaquia, Atotonilco, Tlahuelilpan, Tlamaco y Tlaxcoapan. En todos estos lugares se cultivaba maíz, trigo, algodón, ají y huertas de árboles frutales como membrillos, duraznos, uvas, naranjos e higos. Pero igualmente otros pueblos accedían a las aguas de los afluentes del Tula, el Salto y el Rosas; Xipacoyan y Mixquiahuala lo hacían del primero, Tepeji del segundo, mientras que Xuchitlán del tercero. Mas no únicamente resultaban de importancia los ríos y arroyos, también lo eran los manantiales y los escurrimientos de los cerros y

${ }^{10}$ Robert Cobean y Alba Guadalupe Mastache, “The late Classic and the Early Postclassic Chronology of the Tula Region" en Dan Healan, editor, The Tula of the Toltecs. Excavations and survey, Iowa, University of Iowa Press, 1989, 37 y 39.

${ }^{11}$ Brigitte Boehm de Lameiras, La formación del Estado en el México prehispánico, Zamora, El Colegio de Michoacán, 1986, 213-219 y 278-281; Alba Guadalupe Mastache, "Sistemas de riego en el área de Tula, Hgo.", en Eduardo Matos Moctezuma, coord., Proyecto Tula. Segunda parte, Colección Científica, 33, México, INAH, 1976, 49-70. 
barrancas en tiempo de lluvia. Esta agua era frecuentemente almacenada en presas y jagüeyes, como en Axacuba. ${ }^{12}$

La existencia de riego no significa necesariamente la presencia de grandes obras hidráulicas; en la mayor parte de los casos únicamente se trataba de canales de tierra o tal vez elaborados con pencas de maguey, de pocos metros de longitud, que sólo alcanzaban a regar reducidas extensiones de terreno. La documentación histórica no indica si tales obras de riego del siglo XVI se continuaron utilizando posteriormente y si en algún momento sufrieron ampliaciones o remodelaciones. Seguramente ambas situaciones son posibles, pues gran parte de esos pueblos son mencionados a lo largo del virreinato como lugares donde existía el riego y en los que eran constantes las obras de limpieza y revitalización de la infraestructura hidráulica.

En las siguientes líneas analizaremos tres subregiones: Ixmiquilpan, Tula y Tetepango (en el actual estado de Hidalgo). En las dos primeras los campos de cultivo se bañaban con las aguas del río Tula; en Tetepango se hacía lo propio gracias al río Salado y jagüeyes. Pero mientras en Tula es generalizado el uso de presas y acequias, incluso de considerable longitud, en las otras dos zonas el riego era posible sólo en terrenos muy localizados. En Ixmiquilpan, al igual que en su vecina Tetepango, se usaron otras alternativas como la fabricación de jagüeyes a diferencia de Tula donde su mención es más bien aislada. Lo que resulta significativo en esta amplia región es que los antiguos canales y presas fueron reutilizados y ampliados en el siglo xx, al tiempo de la construcción y planeación de los actuales sistemas de riego.

\section{Sistemas DE RIEGo EN IXMIQUILPAN}

En la introducción al padrón de Ixmiquilpan de 1791 se señala que la jurisdicción estaba habitada por 17 mil almas, pero de acuerdo con nuestro cómputo sólo aparecen registradas 4,094 personas cate-

${ }^{12}$ Francisco del Paso y Troncoso, Papeles de la Nueva España. Geografía y estadística. Tomo I, Suma de visitas de pueblos por orden alfabético, Madrid, Sucesores de Rivadeneyra, Imprenta de la Real Casa, 1905, 2, 21, 22, 60, 125, 126, 143, 166, 193, 194, 209, 220, 223, 224, 226, 289, 310. 
gorizadas como mestizos, castizos y espańoles, e incluye a 198 indios y 18 habitantes cuya adscripción étnica no se especifica; la población indígena aparece eventualmente en los casos en que su conyugue perteneciera a una categoría social distinta. De manera que podemos suponer que la cifra de 17 mil almas es una estimación aproximada de la población total, incluyendo la indígena. Siguiendo tal razonamiento tenemos que, de acuerdo al número total de población estimada, los mestizos computaban $9.1 \%$, los españoles $8.7 \%$, los castizos $2.8 \%$, los mestizindios $1.7 \%$; el grupo mayoritario lo conformaban los indígenas con $77 \%$. De ser así, la disminución poblacional fue considerable a principios del siglo XIX porque para los últimos ańos de la década de 1810 existían aproximadamente 14,084 habitantes en toda la jurisdicción, entre los que se contaban indios, españoles, castizos y mestizos. ${ }^{13}$

Desde los primeros años de la década de 1540, Ixmiquilpan fue un centro económico de mediana importancia regional porque desde entonces, y hasta varias décadas después, su población se dedicó a la explotación de plata abronzada, mucho antes que otros reales del virreinato. Y con la minería llegó la cría de ganado menor que en poco tiempo se convirtió en la actividad económica más relevante. ${ }^{14}$ Localmente, Ixmiquilpan fue uno de los principales abastecedores

13 “Padrón de la jurisdicción de Ixmiquilpan (1791)”, AGN, Padrones, vol. 2, f. 3r y 90r; "Padrón del pueblo de San Agustín (1819)", "Padrón del pueblo de San Agustín Ixtatlaxco (1819)", "Padrón del pueblo de Nuestra Señora de los Remedios (1819)", "Padrón del pueblo de Orizaba (1819)", "Padrón del pueblo del Espíritu Santo Palma Gorda (1819)", "Pueblo del Santuario Mapeté (1819)", "Padrón del pueblo Real del Cardonal (1819)", "Padrón del pueblo de Santa María Coyotepec (alias Tixqui) (1819)", "Padrón del pueblo de San Miguel de la Nopalera (1819)", "Padrón de San Miguel Jonacapa (1819)", "Padrón del pueblo de Santa María Tepexic (1819)", "Padrón del pueblo de Santa Cruz de los Álamos (alias la Pechuga) (1819)", "Padrón del pueblo de Santa Cruz Alberto (1819)", "Padrón del pueblo de Santa Cruz Nequetejé (1819)”, "Padrón de San Juan Bautista (alias San Juanico) (1819)”, срвмnaH, Serie Hidalgo, Rollo 11.

${ }^{14}$ Elionor Melville, A plague of sheep. Environmental consequences of the Conquest of Mexico, Melbourne, Cambridge University Press, 1994; Verenice Cipatli Ramírez Calva, "Itzmiquilpan: un paisaje en construcción. Procesos de reconformación regional, siglos XVI y XVII", Tesis de maestría, Zamora, Centro de Estudios Antropológicos, El Colegio de Michoacán, 2001; Verenice Cipatli Ramírez Calva, Caciques y cacicazgos indígenas en la región de Tollan, siglos XIV-XVII, Colección Investigaciones, Zamora, El Colegio de Michoacán, 2010. 
de hortalizas y productos derivados de las matanzas a los reales mineros como Zimapán y El Cardonal; era un centro mercantil regional en el que se comerciaban gran variedad de productos. En las tiendas y tianguis semanales se intercambiaban semillas, verduras, frutas, pieles curtidas, zapatos, sebo, jabón, papel, seda, petates, reatas y loza, además de otros comestibles y bienes de uso cotidiano. ${ }^{15}$ En general, los pueblos de la jurisdicción combinaban la explotación de ixtle y lechuguilla con la arriería y la cría de ganado menor.

En la primera mitad del siglo xIx, el panorama económico de Ixmiquilpan se presenta complejo. Luego de la cabecera, cuatro eran los centros de población más importantes de Ixmiquilpan por distintas razones: registraban la mayor densidad de población, eran zonas mineras, sitios de paso del tráfico comercial o por su actividad comercial. Uno de esos centros de población era El Cardonal, un real minero donde habitaba el mayor número de españoles de la jurisdicción; estaba localizado en la cordillera norte y para 1819 concentraba $22.1 \%$ de la población total de la jurisdicción. En éste encontramos gran variedad de actividades económicas, entre las que sobresalen: el trabajo en la mina como operarios o jornaleros, los fabricantes de pulque, los jarcieros (que incluye a quienes tejen y tallan lechuguilla) y una reducida porción de labradores. Inmediato a El Cardonal está el otro pueblo de relevancia; Orizaba, de población fundamentalmente indígena, se asentaba en terreno "montuoso y pedregoso", era donde habitaba $9.8 \%$ de la población total de la jurisdicción. El principal comercio de sus habitantes era la jarcia; en segundo lugar, las pieles curtidas; en tercero, las guitarras; y finalmente el carbón. Junto a estos dos pueblos encontramos otros de menor importancia, algunos dedicados al tallado y tejido de lechuguilla como los casos de Mapeté, San Juanico, Los Remedios y Espíritu Santo. Otros pueblos eran más bien de jornaleros y operarios de minas como La Nopalera y Nequetejé; aunque en algunos

${ }^{15}$ Verenice Cipatli Ramírez Calva, "El comercio en las jurisdicciones de Ixmiquilpan, Actopan y Tetepango-Hueypuchtla, siglos XVIII-XIX", Ponencia presentada en el seminario "El comercio y las participaciones indigenas en el siglo XVIII", Zamora, El Colegio de Michoacán, 15-16 mayo, 2008; "Razón estadística de la municipalidad de Yxmiquilpan (1826)", сDвMNAH, serie Hidalgo, rollo 11. 
casos, como en este último pueblo, esas actividades eran tan importantes como la producción de jarcia. A la vez que en Tixqui, cercano a las minas de El Cardonal y La Pechuga, su población era fundamentalmente productora de carbón. Al sur de Ixmiquilpan está otro de los centros de población más importantes, conocido como Chilcuautla. Se ubica a orillas del río Tula, en el camino que conducía de Ixmiquilpan a Tula y la ciudad de México. Contaba con algunos agricultores beneficiados por las aguas del río Tula, aunque la gran mayoría eran jornaleros y arrieros. ${ }^{16}$

Llama la atención que en todos estos pueblos encontramos menciones aisladas a la existencia de labradores, pues las actividades estaban dirigidas a la mina. Al respecto merece especial atención el pueblo de San Agustín. Luego de Ixmiquilpan era el lugar que concentraba la mayor cantidad de población (27.9\%). En él también habitaban gran número de europeos y españoles. Si bien una parte considerable de su población era jornalera en las minas y tejedores, es el único pueblo que registra la existencia de hortelanos; tal vez su producción agrícola haya alimentado a las minas cercanas. Una situación semejante encontramos en aquellos asentamientos ubicados al norte de El Cardonal como Ixtatlaxco, Santa María Tepeji y Jonacapa, cuyos habitantes eran igualmente agricultores. ${ }^{17}$

Ixmiquilpan presenta un clima semiseco, en algunas zonas semicálido e incluso templado subhúmedo con lluvias en verano. La temperatura media anual es de $18.5^{\circ} \mathrm{C}$. La precipitación media anual es de alrededor de los $363.8 \mathrm{~mm}$. En estas circunstancias el riego es una condición indispensable para lograr cosechas medianamente seguras. El pueblo contaba con los medios para hacer frente a tales dificultades medioambientales, pues la cabecera y sus barrios conservaban un lugar estratégico con respecto al río Tula, lo que

16 "Padrón del Mineral de El Cardonal (1819)", "Padrón del pueblo de Orizaba (1819)", "Padrón del pueblo de Nuestra Señora de los Remedios (1819)", "Padrón del Santuario Mapeté (1819)", "Padrón del pueblo del Espíritu Santo de la Palma Gorda (1819)", "Padrón del pueblo de San Miguel de la Nopalera (1819)", "Padrón del pueblo de Santa Cruz Nequetejé (1819)", op. cit.

17 "Padrón del pueblo de San Miguel Jonacapa (1819)", "Padrón del pueblo de San Agustín (1819)", "Patrón del pueblo de San Agustín Ixtatlaxco (1819)", "Padrón del pueblo de Santa María Tepexic (1819)”, op. cit. 
permitió a sus habitantes su aprovechamiento a fin de satisfacer necesidades agrícolas y domésticas. ${ }^{18}$ En su Crónica, Juan de Grijalva describe que el río Tula bañaba gran parte de las huertas localizadas en el centro de Ixmiquilpan: "tiene muy buen río que pasa por las casas, con que riega su vega y así se dan muy buenos frutales y muy buen trigo". ${ }^{19}$ En esos campos se cosechaba algodón, gran variedad de hortalizas, frutas, trigo y maíz. El Padrón de 1791 señala la importancia del río para la población local: "en las orillas del pueblo y del río dispersas sus casitas o jacales y confundidas en la frondedad de las huertas que son muy amenas y abundantes de maíz y frutas exquisitas, no faltando en la rivera corpulentos sabinos". ${ }^{20} \mathrm{La}$ "Razón estadística de la municipalidad de Yxmiquilpan” de 1826 es todavía más explícita al respecto:

a espaldas de la plaza principal del pueblo [al poniente] corre un río muy caudaloso de "agua gorda", su fuente se encuentra en la laguna de Escapusalco junto con el desagüe de Huehuetoca. A él se une el arroyo de Atotonilco [río Salado] de agua termal [¿? ] y otros arroyos estacionales. Este río recorre toda la cabecera desde la hacienda de Deminyó hasta el camino que va hacia Tasquillo y desemboca en el río Moctezuma. El agua del río es de uso común y para regar las labores y hortalizas de todo el pueblo por medio de una zanja. ${ }^{21}$

A esta importante fuente de agua se unían otras. Antiguamente el arroyo Balante pasaba por algunas de las calles centrales y llegaba hasta la plaza principal. Al norte de Ixmiquilpan está el arroyo San Nicolás y El Salitre al noreste; el Panales y los Fierros al poniente. Estas fuentes de agua únicamente eran utilizadas para dar de beber al ganado, no para consumo humano, ${ }^{22}$ ni se tiene registro de que hayan sido utilizados en el cultivo.

${ }^{18}$ Ixmiquilpan, Hgo., 1741, AGN, mapas, planos e ilustraciones, número de mapa: 1361, clasificación: 977/1486, referencia: Tierras, vol. 2160, exp. 8, f. 17.

${ }^{19}$ Juan de Grijalva, Crónica de la orden de N.P.S. Agustín en las provincias de la Nueva España, en cuatro edades desde el año de 1533 hasta el de 1592, México, Porrúa, 1985, 173.

20 "Padrón de la jurisdicción de Ixmiquilpan (1791)", aGN, Padrones, vol. 2, f. 2v.

21 "Razón estadística de la municipalidad de Yxmiquilpan (1826)", op. cit.

${ }^{22}$ Ibidem, s/f. 
En pueblos de la jurisdicción de Ixmiquilpan, al igual que en la de Tetepango y Tula, el cultivo de árboles frutales lo registran las fuentes desde las primeras décadas del siglo Xvi. En la Suma de visitas y, tiempo después, en las Relaciones geográficas del siglo XVI se habla de la abundancia de huertos de higos, duraznos, algodón, ají, trigo, maíz, vid y hortalizas. ${ }^{23} \mathrm{Al}$ sur de la cabecera, en los pueblos de El Alberto y Chilcuautla, también se lograban obtener frutas y hortalizas gracias a su cercanía con el río Tula. En el siglo XviII, las Relaciones geográficas del Arzobispado señalan que en Ixmiquilpan se lograban árboles frutales como duraznos, membrillos, albaricoques, higos y uvas. ${ }^{24} \mathrm{Y}$ para el siglo XIX, la "Razón estadística de la municipalidad de Yxmiquilpan” registra con detalle la variedad de frutas y verduras que se producían en la región como los capulines, garambullos, tunas, chilacayotes, chayotes, calabazas, chirimoyas, zapotes, camotes, duraznos, higos, peras, manzanas, granadas, moras, albaricoques, membrillos, uvas, plátanos, melones y sandías. ${ }^{25}$ Las huertas de árboles frutales, al igual que las hortalizas, estaban localizadas en torno a ríos y arroyos, de manera que ninguna de las dos pueden considerarse prácticas generalizadas. Esta productividad se debía a la existencia de sistemas de riego. En la cabecera había una red de canales alimentados por el río Tula que circundaban al pueblo, construidos en distintos momentos del virreinato. El más antiguo data del siglo xvi y corría desde suroeste del río Tula al noroeste. Este canal lo podemos observar de manera parcial en un mapa de $1741 \mathrm{y}$ luego en otro de 1783; el otro, fue construido en la segunda mitad del siglo XViII bajo la administración de don Diego de Alarcón y Ocańa, alcalde mayor de la jurisdicción.

En cuanto a la zanja más antigua, no sabemos si ya existía antes de la conquista española, pero en el siglo Xvı se sugiere su existencia

${ }^{23}$ Francisco del Paso y Troncoso, op. cit, pp. 21, 120, 125-129; René Acuńa, ed., Relaciones geográficas del siglo XVI, tomo III, México, UNAM-Instituto de Investigaciones Antropológicas, 1986, 31 y 35.

${ }^{24}$ Francisco de Solano, ed., Relaciones geográficas del Arzobispado de México. 1743, tomo I, Madrid, Colección Tierra Nueva e Cielo Nuevo, 28, Consejo Superior de Investigaciones Científicas, Centro de Estudios Históricos, Departamento de Historia de América, 1988, 68.

25 “Razón estadística de la municipalidad de Yxmiquilpan (1826)", op. cit. 
Figura I. Acequia antigua de Ixmiquilpan

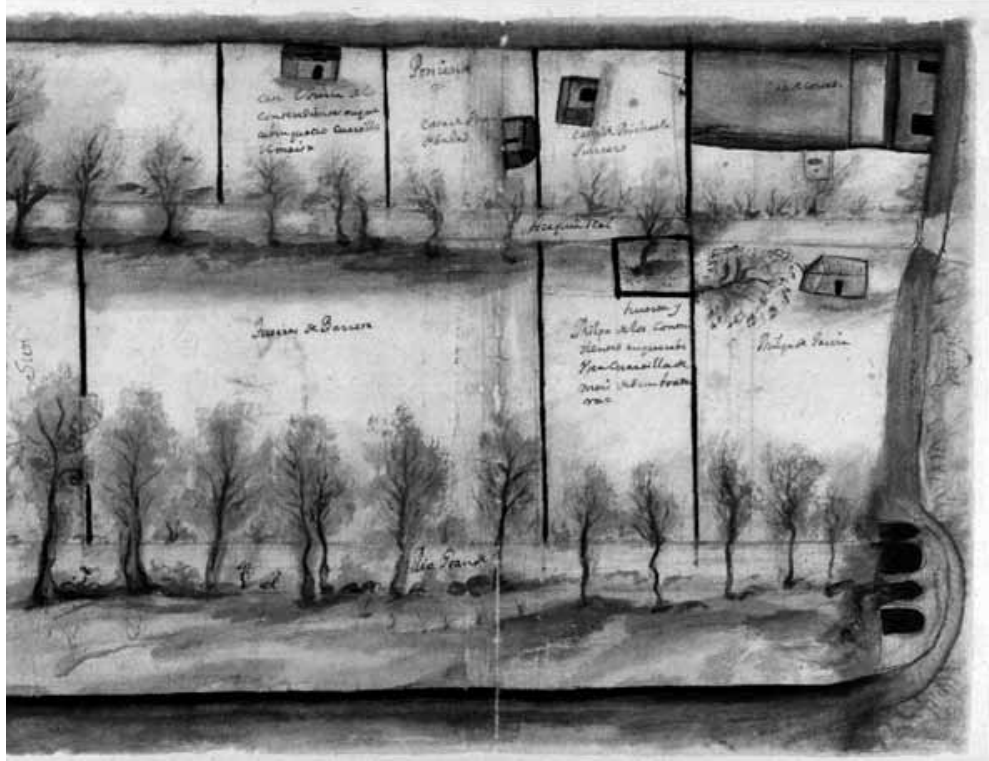

Fuente: AGN, número de pieza: 1361, clasificación: 977/1486, referencia: Tierras, vol. 2160, exp. 8, f. 17.

en la Suma de Visitas y en otros documentos tempranos. En 1563 sufrió una importante remodelación, pues con la intención de tenerla "fija y perpetua" fue reedificada con cal y canto ya que anteriormente había sido construida únicamente zanjando la tierra, sin revestimiento. Ese mismo año, los terrenos ubicados en sus orillas, que en tiempos pasados habían sido de indios principales, fueron repartidos entre sus terrazgueros. ${ }^{26} \mathrm{~A}$ finales del siglo XVII, la acequia era utilizada en común entre indios, mestizos, espańoles y los frailes del convento agustino del pueblo. Poco sabemos de la forma en que se organizaban los usuarios para el riego de los cultivos; sólo hemos encontrado noticia de ello en un documento de 1684 con el que se recordaba la prohibición de dejar que el ganado entrara a la zanja y se recordaba a los agricultores que el convento usaba del

${ }^{26}$ AGN, Mercedes, vol. 7, f. m216r- 218r. 


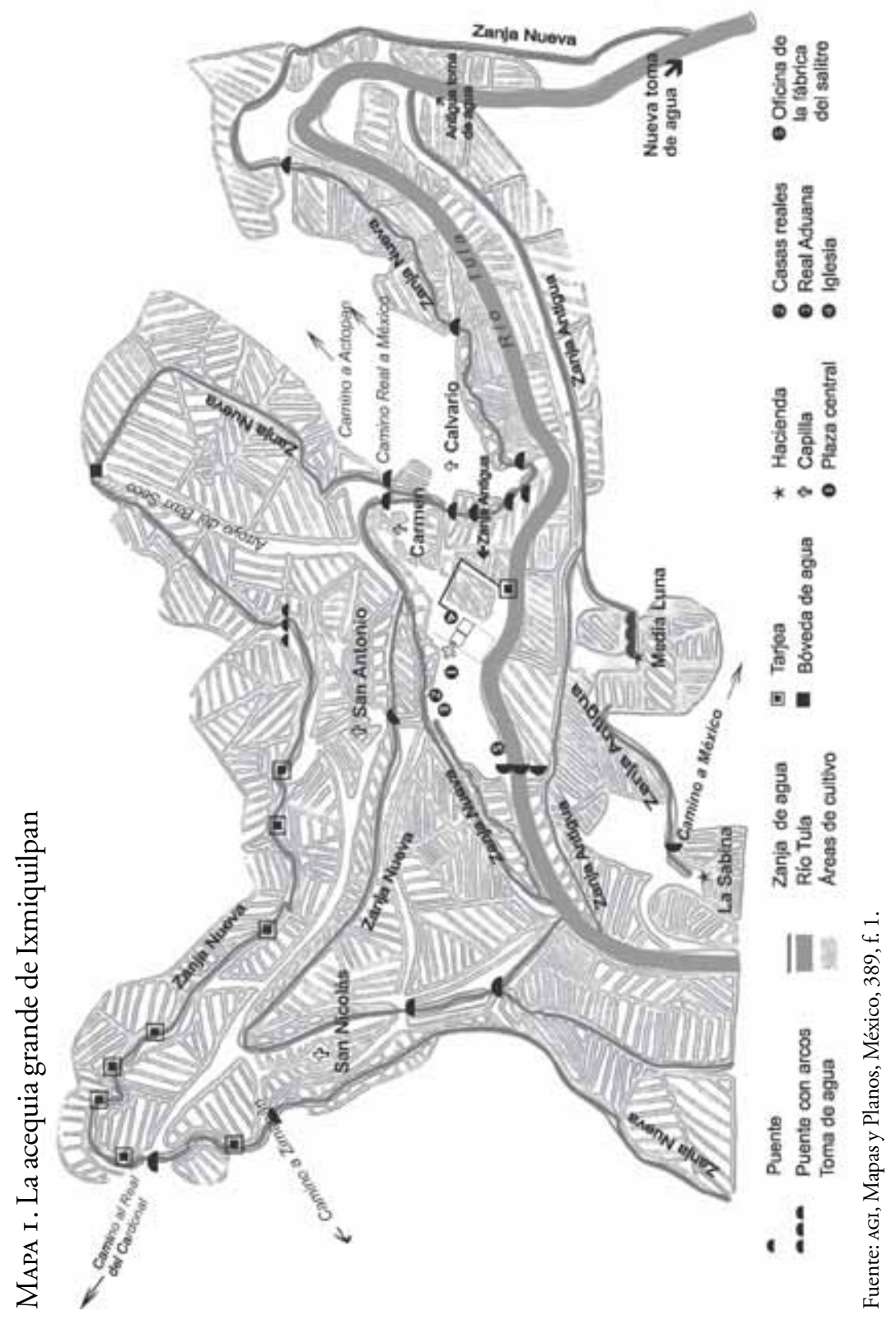


agua para sus sementeras desde horas tempranas del día hasta las cuatro de la tarde. De manera que podemos asumir que el resto del tiempo beneficiaba a los demás cultivadores de los alrededores. Las pugnas entre pueblos de indios y ganaderos por el uso del agua de la acequia del pueblo fueron constantes, a pesar de existir mandamientos virreinales indicando que tal obra sólo debía beneficiar a los agricultores. Ni mucho menos importaba a los arrieros y ganaderos que hubiese abrevaderos, prueba de ello es que sistemáticamente hicieron caso omiso de las disposiciones de la Audiencia e introducían sus ganados en la zanja. ${ }^{27}$ En 1688, los gobernadores de Ixmiquilpan y Tlazintla, al igual que el alcalde mayor de la jurisdicción, informaban a la Audiencia que la acequia tenía una legua y media de largo; con sus aguas se bañaban los sembradíos de maíz y trigo, utilizados para abastecer a la cabecera, a los reales de Pachuca y Zimapán. ${ }^{28}$

Ignoramos por qué casi 20 ańos después, la citada zanja estaba en ruinas, abandonada y azolvada. Ocurrió entonces que el maíz y el trigo se tuvieron que introducir desde Celaya a pesar de que su transportación resultaba ardua y costosa al no contar con animales de carga necesarios, y al comerciarlo en el pueblo su precio resultaba elevado para la población. Desde que el canal dejó de funcionar los cultivos estuvieron a merced del tiempo, a veces se perdían por las sequías y otras por el exceso de lluvias. Con esa preocupación, en 1717 , se reunieron los alcaldes, regidores y el gobernador de Ixmiquilpan, concluyeron que antiguamente esas tierras habían sido de riego pues aún quedaban vestigios de la antigua acequia y tomas. $\mathrm{Su}$ revitalización sería provecho de todos, así españoles e indios podrían regar cerca de 60 fanegas de sembradura de maíz. ${ }^{29}$ Gracias a la revitalización de ese canal y a la construcción de uno nuevo, hacia la segunda mitad de dicho siglo Ixmiquilpan nuevamente volvió a ser uno de los principales productores de trigo de los contornos, junto

${ }^{27}$ AGEH, Fondo Tula, Sección Justicia, Serie: Administración de Justicia, caja 5, exp. 27, f. 1r.; AGN, Indios, vol. 7, exp. 314, f. 156r.

${ }^{28}$ AGN, Indios, vol. 30, exp. 187, f. 176v, 177v.

${ }^{29}$ AGN, Indios, vol. 41, exp. 146, fs. 177r-178v. 
con Actopan y tres sujetos de Tetepango-Hueypuchtla-Axacuba, Atitalaquia y Mixquiahuala. ${ }^{30}$

En 1783, Diego de Alarcón Ocaña, informaba al virrey que en Ixmiquilpan las lluvias eran escasas y erráticas por lo que gran parte de las tierras de la cabecera no se podían cultivar con provecho; no se había ideado una manera de utilizar el agua del río Tula para el riego de los campos de la zona norte y oriente, de manera que Alarcón planeó la construcción de una acequia que rodeara esos terrenos. Si bien, al suroeste del río Tula corría la zanja antigua que al parecer nacía en las inmediaciones del barrio del Maye, al sur de la cabecera, y se prolongaba hacia el norte hasta desembocar nuevamente en el río, lo cierto es que no alcanzaba a regar otros cultivos fuera de esta zona.

La Zanja Nueva o Acequia Grande, como se le conoció a la obra ideada por Alarcón, tenía tres varas de largo; según Alarcón su obra podía regar 200 fanegas de maíz y 800 de trigo. Contaba con atarjeas y sangrías que conducían el agua a los cultivos, puentes que permitían la comunicación y bóvedas sobre las que se dirigía el agua. Nacía al sur del pueblo, río arriba de la Zanja Antigua, y al llegar a la altura de la capilla del cuartel del Carmen se bifurcaba; mientras un ramal rodeaba los campos de cultivo del oriente y norte de los barrios de San Antonio y San Nicolás, la otra vertiente pasaba junto a la plaza central y las casas reales para desembocar nuevamente en el río Tula. De este último ramal se desprendía otro que igualmente cruzaba por los barrios antes dichos. Del río Tula también se derivaba otra acequia que regaba las huertas del convento agustino para luego llegar hasta su interior (véase mapa 1). Acerca de su importancia para el pueblo el Padrón de 1791 indica: "sin el auxilio de la zanja o sangría que se le hizo al río Grande [río Tula], carecería este pueblo de los beneficios y frutos que hoy tiene"; gracias a ella las casas se dispersaban por las orillas del río "confundidas en la frondosidad de las huertas, que son muy amenas y abundantes de maíz y frutas exquisitas, no faltando en la ribera corpulentos sabidos, abundancia de árboles del Perú, sauces

${ }^{30}$ Felipe I. Echenique March y Lourdes M. Romero Navarrete, op. cit., pp. 92-93. 
y álamos blancos" ${ }^{31}$ El Padrón de 1791 indica que en las tierras que se beneficiaban de la Acequia Grande se obtenían hasta tres mil fanegas de maíz y mil de trigo, mucho más de lo estimado por Alarcón pocos años antes. ${ }^{32}$ Desafortunadamente no contamos con información acerca de las formas en que los usuarios se administraban para el abasto del agua y el mantenimiento de la obra de Alarcón, seguramente posteriores incursiones en las fuentes históricas darán cuenta de ello.

Pero el cultivo de trigo no se constreñía a los terrenos cercanos a la Acequia Grande, la "Razón estadística de la municipalidad de Yxmiquilpan” proporciona información puntual acerca del cultivo de semillas en otras zonas. En las haciendas de Debodé y San José Deminyó se sembraba maíz, cebada, trigo y frijol. En los ranchos de Santa María Buenavista, La Viña, Estanzuela, Bondo, La Sabina y Media Luna se calculaba una producción de treinta fanegas de maíz de riego, cincuenta de frijol, cuarenta de trigo, treinta de cebada, diez de alverjón, haba y lenteja. Las siembras de maíz y frijol de riego se efectuaban en los meses de marzo y abril, y la cosecha se levantaba en agosto y septiembre, registrándose una segunda siembra en los meses de noviembre y diciembre. El alverjón, haba y cebada se cultivaban en noviembre y diciembre, y ya en abril y mayo se podían recoger los frutos. El cultivo de semillas se hacía fundamentalmente en tierras de riego, pues en las de temporal la cosecha quedaba a merced de las escasas lluvias. ${ }^{33}$

Fuera de la cabecera había igualmente pueblos que contaban con riego. Tlacotlapilco y Chilcuautla igualmente aparecen en las fuentes tempranas como poseedores de sistemas de riego, y de hecho están próximos al río Tula. Chilcuautla se localiza a media legua del río, poseía además tres ojos de agua "buena" al pie de tres cerros en los ranchos de San Antonio, El Gavillero y Xhitey, además tenía dos arroyos de agua de lluvia: el Zońé y San Miguel. ${ }^{34}$ Sin embargo, en 1735 los indios de Tlacotlapilco decían no tener ningún agua con qué bañar sus cultivos, pues por los cuatro rumbos:

31 "Padrón de la jurisdicción de Ixmiquilpan (1791)", op. cit., fs. 2v.

${ }^{32}$ Felipe I. Echenique March y Lourdes M. Romero Navarrete, op. cit., pp. 92-93.

33 "Razón estadística de la municipalidad de Yxmiquilpan (1826)", op. cit.

${ }^{34} \mathrm{Ibidem}$, s/f. 
son serranías, pedregales, barrancas, planes tepetatosos, bosques de espinos en que se incluyen muy cortos pedacillos o manchones de algunas milpillas en tierras muy delgadas y en que todo ello a lo sumo y alargar distancias unos de los otros y en lo que hace al asiento del pueblo todo es un pedregal colgado, todo tepetate, en que no se descubren ningunas tierras de pan llevar. ${ }^{35}$ ser todo aún desde la misma puerta del cementerio cerro pedregoso sobre tepetate, salitroso, infructífero y que por el rumbo del poniente hasta el río hallan el mismo defecto, porque aunque por este rumbo a la vera del dicho río se halla un llanete muy angosto este también es salitre, y arena de la que en las crecientes trae el río. ${ }^{36}$

Las tierras más fértiles se hallaban a la parte sur y este de Ixmiquilpan, en los pueblos y barrios sujetos a la parcialidad de Tlazintla, todos ellos se encontraban en torno al río Tula y el arroyo Tecolote; y en sus tierras brotan gran cantidad de manantiales. ${ }^{37}$ De manera semejante a lo ocurrido en la cabecera de Ixmiquilpan, encontramos que con el paso del tiempo los pueblos de indios dejaron azolvar los canales. Esto parece haber sido un proceso casi generalizado en la región entre finales del siglo XVII y los primeros años de la siguiente centuria; posiblemente se haya debido a la falta de organización de los usuarios o a pleitos irreconciliables surgidos entre ellos. En algunos casos, como Ixmiquilpan, la revitalización de las obras hidráulicas se dio a principios del siglo XviII, pero en otros, como Tlazintla, eso ocurrió décadas después. Por ejemplo, ante la escasez de agua en 1764 los barrios del Maye y el Fitzhi consideraron la necesidad de revitalizar una zanja, que reconocían como antigua, pero que para

35 "Vista de ojos, Tlacotlapilco (1735)", AGN, Tierras, vol. 1660, exp. 3, f. 50r.

36 "Medida de las 600 varas, Tlacotlapilco (1735)", AGN, Tierras, vol. 1660, exp. 3, f. 53v.

37 "Despacho expedido a los naturales del pueblo de Tlazintla y La Sabana para que se notifique a los dependientes de la hacienda de don Javier Paulín dejen libremente usar a dichos naturales del agua, monte y demás (1778)", AGN, Indios, vol. 65, exp. 388, f. 316v; "Queja presentada por don Juan Martín Gabrieles, vecino del pueblo de Tlazintla, contra la presa que pretende hacer el capitán Antonio Paulín en el cerro Bagandó (1810)", AGn, Tierras, vol. 2870, exp. 11, fs. 2r-3r; "Autos promovidos por Agustín Miguel, Calixto Mendoza y demás naturales del pueblo de Ixmiquilpan sobre que se les confirme la distribución de las aguas de la acequia que limpiaron (1765)", AGN, Tierras, vol. 2127, exp. 7, f. 2v, 8r-9v; "Pleito entre Juan de la Cruz y los vecinos del barrio de Tasguadá sobre el uso de un jagüey (1797-1800)", AGN, Tierras, vol. 2891, exp. 3, f. 1v y 7r. 
MAPA 2. Jagüeyes y presas al sur y oriente de Ixmiquilpan

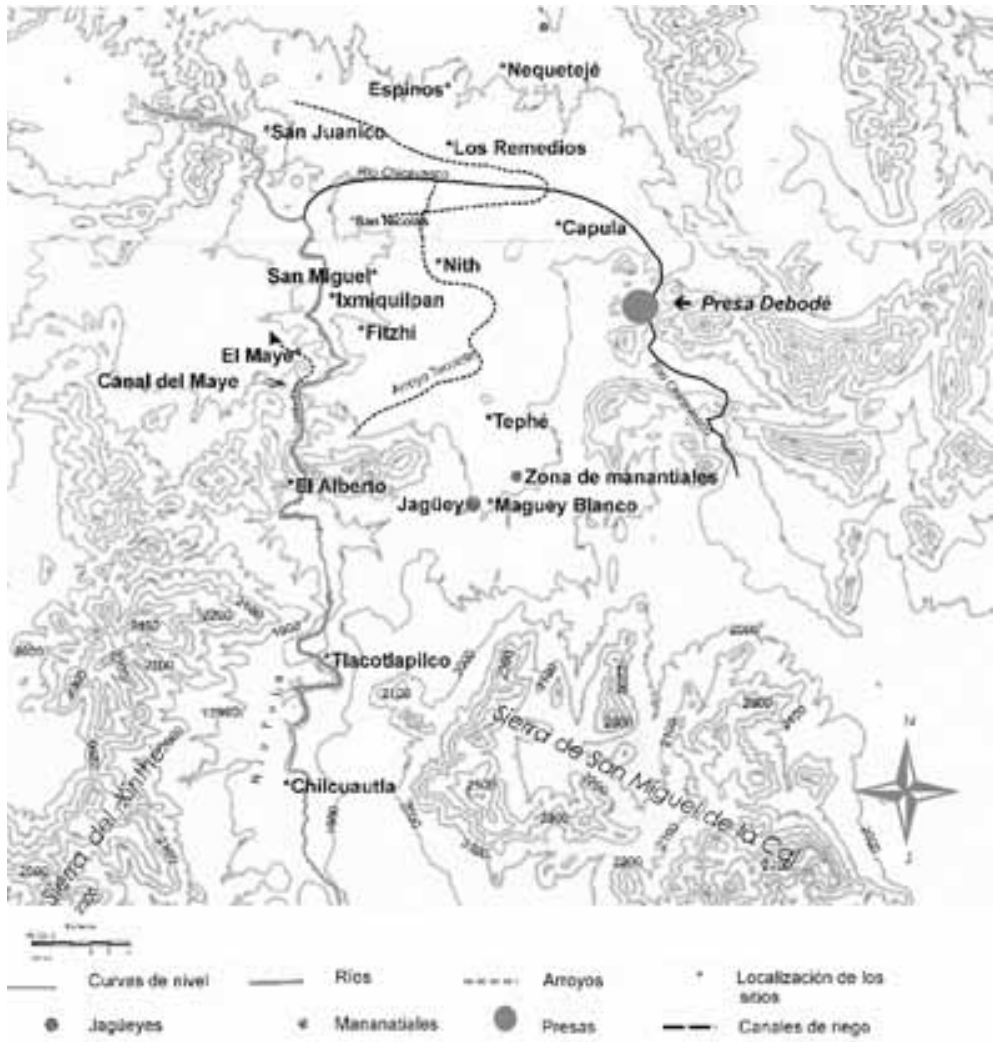

Fuente: INEGI. Cartas topográficas 1:50,000: Ixmiquilpan F14C7, Mixquiahuala F14C89.

entonces estaba azolvada. Al parecer, la toma de agua se originaba en el río Tula, en tierras del Fitzhi y cruzaba por zonas agrícolas del Maye. Éste es un canal que en la actualidad continua en operación y en aquel entonces beneficiaba a cerca de 80 usuarios, en su mayoría indios, dueños de terrenos cercanos. Nos referimos a la llamada zanja antigua, de la que hablamos líneas arriba ${ }^{38}$ (véanse mapas 1 y 2).

38 "Diligencias hechas a pedimento de don Manuel y demás naturales sobre que las diligencias practicadas por su gobernador de repartimiento de aguas (1764)", AGN, Tierras, vol. 2127, exp. 7, 9fs. 
El río Tula no era la única fuente de agua que gozaba Tlazintla, pues al este del barrio del Fitzhi corría el arroyo Tecolote originado al norte de El Alberto, en las inmediaciones del río Tula. Las aguas de ese arroyo bañaban un amplio valle comprendido entre Ixmiquilpan, el barrio del Tephé, el de Bagandhó, Capula y el Nith. En varias ocasiones, los indios intentaron cambiar su rumbo (que va de sureste a noreste), pues en tiempo de lluvias su caudal solía ser aún mayor que el del Tula, ocasionando graves inundaciones a la cabecera. Hacia el este encontramos la presa Debodé, de la hacienda del mismo nombre. Se alimentaba de las escurrideras de los cerros Bagandhó y Capula, y de las aguas del río Chicavasco, que a su vez recoge las avenidas del río del mismo nombre. Fue construida en el siglo XviII por el capitán don Antonio Paulín y regaba las tierras de la hacienda y los pueblos cercanos. ${ }^{39}$ Actualmente la presa continúa en funcionamiento.

Diversos barrios de la antigua Tlazintla son conocidos hoy en día porque en ellos nacen importantes manantiales de agua termal, como por ejemplo, Maguey Blanco y el Tephé. En los barrios El Alberto y Maguey Blanco existía un jagüey de 88 varas de norte a sur, por 92 y 45 varas en sus otros lados, cuya agua era utilizada en la agricultura. Los cultivos eran regados a través del sistema de melgas; para ello se dejaba correr el agua por medio de canales hasta anegar los surcos. El jagüey era propiedad del común del barrio de Maguey Blanco; sus tributarios lo habían abierto a mediados del siglo xviII e igualmente entre todos se organizaban para su constante limpieza. ${ }^{40}$ Ser beneficiario del agua implicaba no sólo tener terrenos en el pueblo sino también ser tributario de él. En 1796, estalló un conflicto por la propiedad de dicho jagüey entre Juan de la Cruz, del vecino barrio de El Alberto y los naturales de Maguey Blanco. Según las declaraciones de Juan de la Cruz, el jagüey fue abierto por su padre en tierras que la república le había asignado como tributario. Cuando su progenitor murió heredó una parte de las tierras, en las que se

39 “Padrón de Ixmiquilpan (1791)”, op. cit., f. 2v; "Juan Martín reclamando la presa que ha puesto el capitán Paulín con que le ha privado y a muchos del riego a sus sementeras (1820)", AGN, Tierras, vol. 2870, exp. 11, 10 fs.

40 "Certificación de don Manuel Ventura, gobernador de Tlazintla, Ixmiquilpan (1793)”, aGN, Tierras, vol. 2891, exp. 3, fs. 9v-13r. 
incluía el jagüey. De acuerdo con sus quejas, sus vecinos detectaron el provecho que implicaba su limpieza y mantenimiento, de manera que se lo apropiaron, haciéndolo pasar como parte de los bienes de comunidad. Por su parte, el gobernador y alcaldes del pueblo argumentaban que Juan de la Cruz había sido astuto en su proceder, pues trasladó su casa a las inmediaciones del jagüey y ya instalado en el lugar lo cercó con la intención de que ningún otro pudiese beneficiarse del agua. ${ }^{41}$ Finalmente, el jagüey fue abierto por los beneficios que aportaba a la colectividad.

A diferencia de la cabecera y de la zona sur y noreste, los pueblos al norte de Ixmiquilpan localizados sobre cerros y laderas presentaban dificultades para acceder al agua; la excepción la constituyen la Sabana y Orizaba que contaban con reducidos sistemas de riego derivados de jagüeyes y arroyos (véase mapa 3 ). En esta zona el uso de agua entre pueblos de indios y haciendas de beneficio de metales también fue producto de constantes y enconados litigios, ejemplo de ello tenemos el caso de Francisco Meléndez, dueño de las minas llamadas la Santísima Trinidad y Señor San Joseph, ubicadas el paraje de la Pechuga, al norte de Ixmiquilpan. Para el beneficio de los metales, Meléndez labró dos haciendas o ingenios de fundición, llevando el agua necesaria de dos arroyos cercanos. Según él, su hacienda resultaba de gran provecho para los naturales del pueblo de Orizaba, pues no sólo les compraba carbón sino que además les daba trabajo en las minas. A pesar de ello, los indios se mostraban empeńados en sabotear sus trabajos, destruyendo sus ranchos y sangrando los arroyos, de los cuales él tomaba el agua que requería, provocando que llegara menos cantidad de la necesitada para el trabajo de su ingenio. A pesar de haber cerca de seis leguas entre el pueblo y el ingenio, los indios de Orizaba alegaban que los terrenos donde estaba la hacienda de beneficio les pertenecían y por ello habían hecho sus milpas en ellos. ${ }^{42} \mathrm{En}$ la vista de ojos que realizó el alcalde mayor de la jurisdicción, encon-

41 "Queja de Juan de la Cruz, Ixmiquilpan (1796)", AGN, Tierras, vol. 2891, exp. 3, fs. 2r-3r; "Queja del común y naturales de El Alberto (1797)", AGN, Tierras, vol. 2891, exp. 3, fs. 4r-6v.

42 "Carta de don Miguel de Salazar a la Real Audiencia (1779)", AGN, Tierras, vol. 2150, exp. 1, fs. 4r-4v. 
MAPA 3. Jagüeyes al norte de Ixmiquilpan

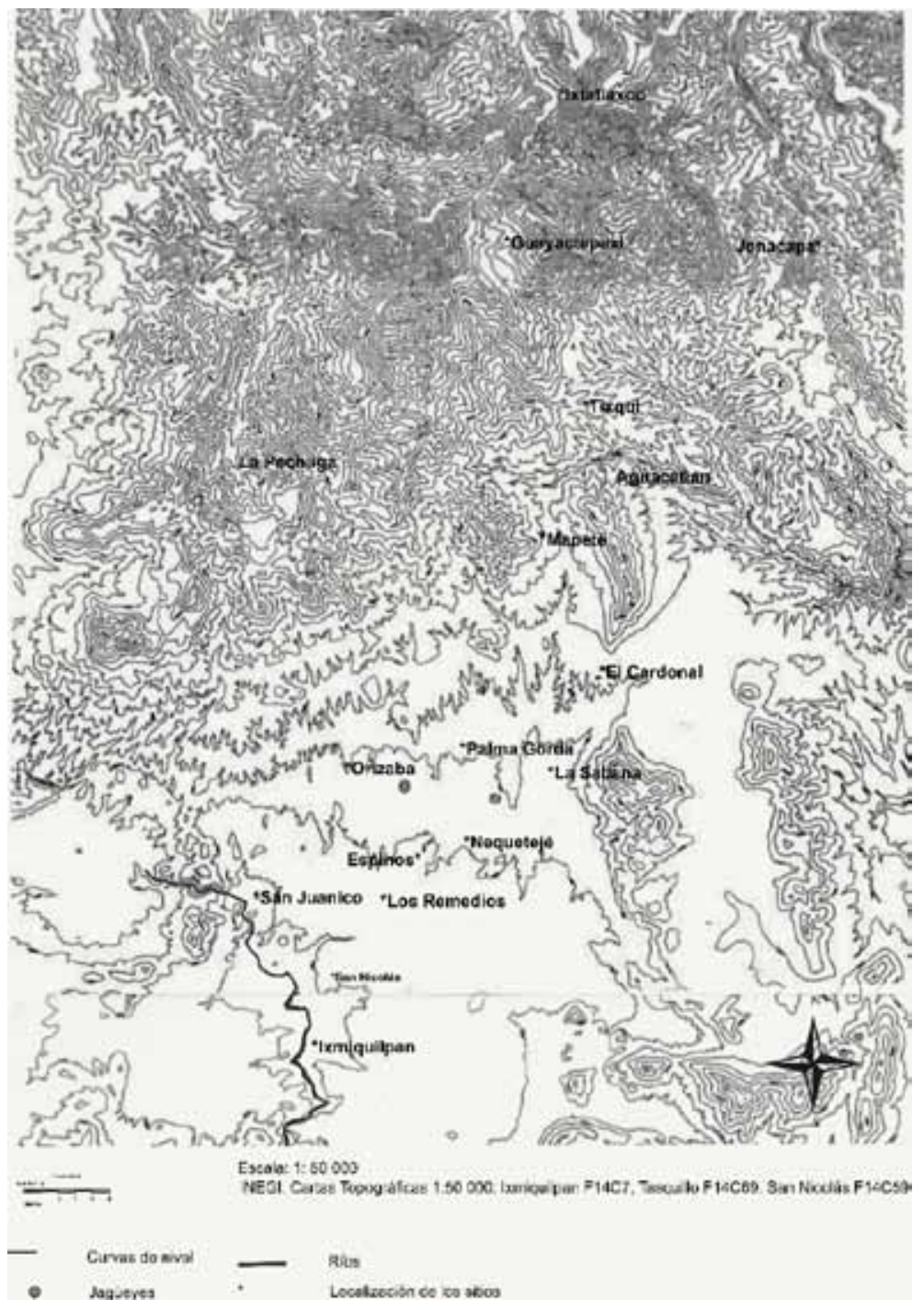

Fuente: INEGI. Cartas topográficas 1:50,000: Ixmiquilpan F14C7, Tasquillo F14C69, San Nicolás F14C59. 
tró que ciertamente los indios habían derruido las construcciones hechas por Meléndez y en su lugar habían cultivado maíz; e igualmente, los indios sangraban los arroyos cercanos provocando que llegara menos agua al ingenio. Aunado a la falta de agua, las minas no podrían producir plata durante todo el año pues los indios se negaban a trabajar en ella. Si bien, el alcalde mayor reconocía que los títulos de propiedad correspondían a Orizaba, encontraba de mayor provecho que, teniendo tierras en las inmediaciones de su pueblo, dejasen libres las que solicitaba Meléndez. Con ese mismo espíritu el fiscal de la Audiencia determinó, que a pesar de que las tierras eran del pueblo, debían dejarse para provecho de Meléndez pues eran para un beneficio de metales. Lo interesante de este caso es que pocos años después, en 1819, los padrones de población ya no registran la existencia de agricultores en ese pueblo, únicamente curtidores, jarcieros, carboneros y guitarreros.

\section{El CASo de Tetepango y sus CONTORNOS}

Su población no india ascendía a 4,222 almas, de las cuales $41.7 \%$ eran españoles, $15.6 \%$ castizos y $42.6 \%$ mestizos, la mayoría de ellos vivían en las haciendas y ranchos cercanos. ${ }^{43}$ En 1794, el virrey conde de Revillagigedo ordenó a los subdelegados informar del número de tributarios de sus jurisdicciones; el encargado de Tetepango, Bernardo José de la Torre, informó ese mismo año que en la jurisdicción a su cargo y sus sujetos, incluidos los ranchos y haciendas, existían 16,255 almas; entre 14,103 y 13,450 eran indios, es decir, constituían entre 86.7 \% y 82.7 \% con respecto a la población total. De ellos 3, 090.5 (aproximadamente $21.9 \%$ y $22.9 \%$ ) eran tributarios. El número de españoles era de 2,152 (13.2\%). ${ }^{44}$ Tan sólo cuatro años después el número de tributarios había aumentado a razón de $0.15 \%$ aproximadamente; con respecto al periodo ante-

43 "Relación de pueblos haciendas y ranchos de la jurisdicción de Tetepango (1791)", AGN, Padrones, vol. 18, fs. 3r-115v.

44 "Padrones mandados a hacer por el virrey conde de Revillagigedo. Padrón de Tetepango (1794)", AGN, Indiferente Virreinal, caja 1025, exp. 3, f. 17r-17v. 
rior, para entonces los tributarios eran $3,112 .{ }^{45}$ Hacia principios del siglo XIX la población aumentó nuevamente; según Peter Gerhard, para 1803 había 4,540 tributarios. ${ }^{46} \mathrm{Y}$ en 1806 Lucas Wading y Geraldino, subdelegado de la jurisdicción, informaba a la Audiencia que se contaban 5,239 tributarios y 5,704 en 1807. ${ }^{47}$

Desde los primeros tiempos del virreinato, la población de Tetepango fue requerida constantemente en los trabajos de las haciendas de labor de Cuauhtitlán y Tepozotlán. Sus principales actividades económicas, tanto de indios como españoles, eran el cultivo de maíz y trigo, la cría de ganado menor, especialmente de ovejas. ${ }^{48}$ Adicionalmente, la población indígena explotaba las caleras ubicadas en las inmediaciones. En el siglo xviII los cultivos eran maíz, frijol, trigo, cebada, haba, alverjón y chile.

Gran parte de las tierras que conforman la jurisdicción son llanuras y lomeríos. Cuenta con algunos manantiales y pozos que son abastecidos con el agua de las lluvias. El clima es templado, con una temperatura media anual de alrededor de los $17^{\circ} \mathrm{C}$, una precipitación pluvial de $900 \mathrm{~mm}$ por año. Las fuentes históricas registran un clima extremoso como lo sigue siendo actualmente. En 1785 se perdió la cosecha de semillas por las intensas heladas, "con las cuales totalmente se arruinaron y aniquilaron las milpas y sembrados de esta dicha jurisdicción, quedando como ha quedado todos sus vecinos reducidos a la mayor escasez". El año anterior se había registrado una fuerte sequía, que redundó en la falta de pastos para los ganados y consecuentemente éstos murieron de sed y hambre. Igualmente, las siembras de maíz y frijol fueron muy reducidas y en su mayor parte se perdieron. Para 1793, nuevamente la sequía se hizo presente. ${ }^{49}$

45 "Matrícula de tributarios de Tetepango (1798)", AGN, Indiferente Virreinal, caja 0922, exp. 7, f. 1r.

${ }^{46}$ Peter Gerhard, Geografía histórica de la Nueva España, 1519-1821, México, unAM, $2000,307$.

47 "Cuaderno de las cuentas de comunidad de Tetepango (1806)", AGN, Indiferente Virreinal, caja 5408, exp. 23, fs. 1r-57r; "Pliego de las resultas y reparos en la iglesia de cuentas de bienes de Tetepango (1808)", AGN, Indiferente Virreinal, caja 5408, exp. 22, 9fs.

${ }^{48}$ Antonio Villaseñor y Sánchez, Teatro americano..., p. 146.

${ }^{49}$ AGn, Tributos, vol. 55, exp. 4, f. $184 \mathrm{v}$ y $215 \mathrm{r}$; "Cosechas y temporales de los seis meses segundos de 93 (1794)”, AGN, Indiferente Virreinal, caja 3346, exp. 9, f. 30r. 
También la primera mitad del año 1809 se caracterizó por falta de agua; no obstante, en este caso, los cultivos la pudieron superar, pues las lluvias cayeron antes de lo esperado; mas no sólo hubo abundantes lluvias sino también fuerte granizo. Por ello es que ocho años antes, en 1801, Juan Nepomuceno Bretón, subdelegado de la jurisdicción, con certeza informaba que el campo estaba "sujeto a las aguas temporales". Y a pesar de que era una zona cubierta de abrojos, magueyes, cardones y biznagas, sujeta a las constantes heladas, el granizo, lluvias abundantes o muy escasas, las cosechas se lograban medianamente con éxito pues una parte de los campos eran de riego. ${ }^{50}$

Pueblos como Atitalaquia, Tlaxcoapan y Tlahuelilpan eran especialmente beneficiados con el agua del río Salado. A principios del siglo XVIII, existió una presa construida por los indios de Atitalaquia en las inmediaciones del pueblo de Tlamaco, conocida con el nombre de la Reyna. En 1746, el gobernador del pueblo declaró ante el alcalde mayor de la jurisdicción que la presa era una construcción antigua pues había sido edificada aproximadamente cien años atrás: "de inmemorial tiempo a esta parte, para socorrer nuestras sementeras con riego, faltándoles el agua del cielo, nuestros antecesores y causantes fabricaron en el río que cruza por este pueblo una presa de la cual por zanjas, pesada y medida, el agua se ha conducido y conducimos a las milpas". ${ }^{51}$ De la presa se derivaba una zanja que al parecer regaba las tierras no sólo de Atitalaquia sino también las de su vecino inmediato Tlaxcoapan, según los informes del propio gobernador. Los de Atitalaquia utilizaban el agua desde la madrugada hasta la puesta del sol; después de ese tiempo abrían las compuertas para dejar correr el líquido hacia los pueblos de Tlahuelilpan y Tlaxcoapan $^{52}$ (véase mapa 4).

50 "Relación que manifiestan los temporales y cosechas de la jurisdicción de Tetepango en los primeros seis meses de este ańo de 1809", AGN, Indiferente Virreinal, caja 5784, exp. 29, f. 1r; AGN, Indiferente Virreinal, caja 3521, exp. 1, f. 1r; "Relación de los temporales y cosechas de la jurisdicción en el segundo semestre de 1808”, AGN, Indiferente Virreinal, caja 3497, exp. 17, 13 fs.

51 "Los caciques y común de los naturales de la cabecera de Atitalaquia con los de los pueblos de Tlaxcuapan y Tlahuelilpan de Misquiahuala sobre el goce de las aguas del río de dicho pueblo de Atitalaquia”, AGN, Tierras, vol. 1470, exp. 4, 1 r.

52 Ibidem, f. 1r. 
Mapa 4. Sistemas de riego de Tetepango y sus sujetos

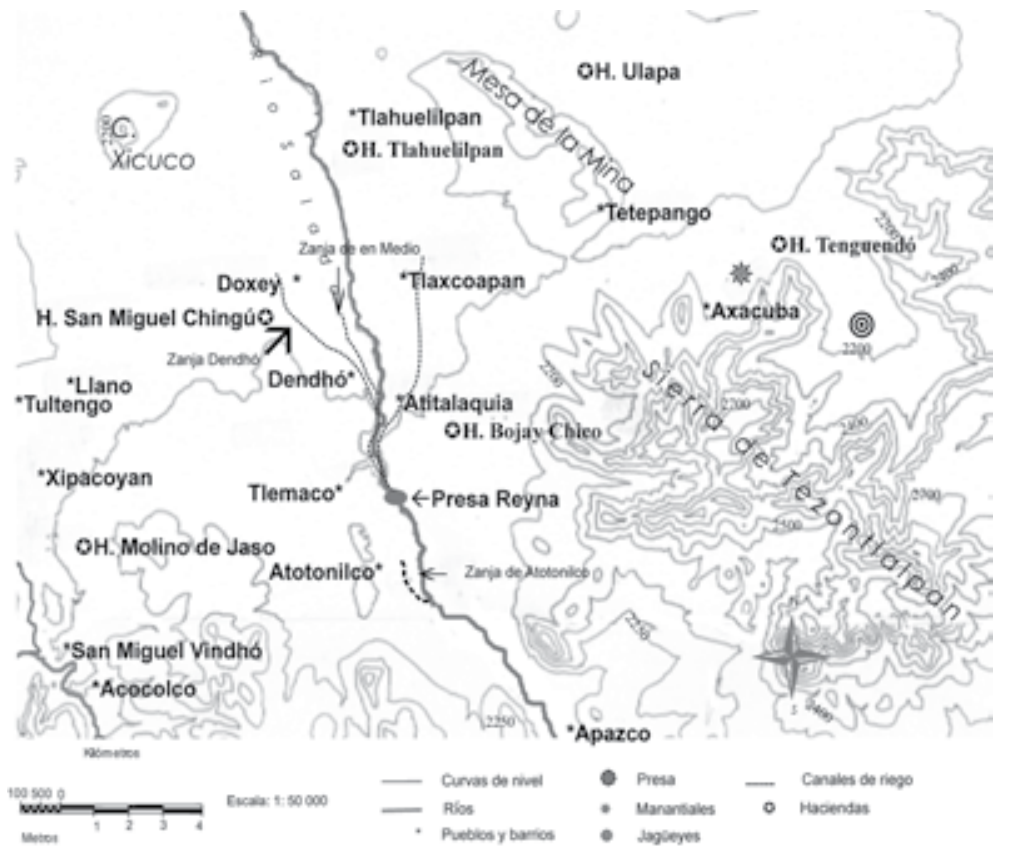

Fuente: INEGI. Cartas topográficas: Tula F14C88, Mixquiahuala F14C89, Tepexi E14A18, Zumpango E14A19.

La presa de la Reyna sufrió constantes reedificaciones y cambios de ubicación a lo largo del siglo XviII a causa de fuertes avenidas del río que terminaban por destruirla. La primera presa de que tenemos registro ya existía en 1732; se había edificado hacía al sur de otra más antigua. En esta obra participaron los indios de Tlahuelilpan, Atitalaquia y Tlaxcoapan, y el apoyo del entonces dueño de la hacienda Chingú, Manuel Romero. De la presa se derivaba la zanja que regaba las tierras de los indios; ${ }^{53}$ contenía tres de las seis melgas que llevaba el río y regaba cerca de 40 fanegas de trigo y maíz. Entre 1770 y 1772, aproximadamente, la presa sufrió nuevamente el embate del agua,

53 "Autos de don Bernardo Pérez de las Cuevas, depositario de la hacienda nombrada San Miguel en la jurisdicción de Atitalaquia, con el gobernador y naturales de dicha jurisdicción sobre unas zanjas (1732)", AGN, Tierras, vol. 1895, exp. 2, f. 2r-30r. 
quedando inservible. Entre esos ańos y 1782, posiblemente, la presa fue nuevamente construida, pero esta vez cambió nuevamente de ubicación. No sabemos con exactitud si el proyecto tuvo buen término pues las quejas presentadas por don Luis Gonzaga González Maldonado, entonces dueño de la hacienda Chingú, al igual que los dichos de sus testigos dejan entrever que la antigua continuaba en uso a pesar de su deteriorado estado. Un documento de 1791 indica claramente que por temor a Luis Gonzaga los indios cesaron en su intento temporalmente. Este año los indios solicitaron nuevamente a la Audiencia se les permitiera levantar la obra, pero esta vez sus principales opositores fueron los dueńos de la hacienda de San Servando Tlahuelilpan, los condes de la Cortina. El problema es que para entonces no sólo Atitalaquia represaba el agua, sino que también lo hacia Tlaxcoapan y Chingú, río abajo; de manera que en una fuente con tan poco caudal como el Salado ocasionaba que el resto de los pueblos por donde pasaba ya no alcanzaban a gozar del vital líquido. ${ }^{54}$

Hacia el poniente, se encontraban la zanja actualmente conocida como Dendho y otra derivada de ella llamada la Zanja de en Medio, ambas fueron hechas tanto por los indios del barrio de Doxey como por los dueños de la hacienda San Miguel Chingú. Hasta antes de 1823, la zanja principal era utilizada para la conducción del agua a Chingú y a la hacienda de Tlahuelilpan y al barrio de Doxey. La zanja principal se originaba en el río Salado, a pocos metros de donde nacía la perteneciente a Atitalaquia, y se prolongaba varios kilómetros al norte, cruzando los terrenos este pueblo. Fue abierta antes de 1732 por Bernardo Pérez de las Cuevas y originalmente se alimentaba de una presa, tal vez de la Reyna, pero cuando ésta se derruyó, más o menos en 1725, fue conectada directamente al río. ${ }^{55}$ En 1823 se abrió la Zanja de en Medio por los habitantes de Doxey. Para el uso de ambos canales el barrio y Chingú hicieron un reglamento, que estipulaba

54 "El común del pueblo de San Pedro (Tlaxcoapan) con el señor conde de la Cortina sobre reedificación de una presa (1790)", AGN, Tierras, vol. 2861, exp. 8, f. 122v-128v; "Información de prueba dada por parte del Dr. Don Luis Gonzaga González Maldonado sobre el reedificio de una presa (1782)", AGN, Tierras, vol. 2369, exp. 3, f. 5r-18r y 122v-128v.

55 "Autos de don Bernardo Pérez de las Cuevas, depositario de la hacienda nombrada San Miguel en la jurisdicción de Atitalaquia, con el gobernador y naturales de dicha jurisdicción sobre unas zanjas (1732)", op. cit., f. 26r-26v. 
una serie de compromisos en los que se indicaba que los gastos originados por canales serían costeados por los vecinos del barrio. Para que el conducto principal estuviera corriente todo el día era indispensable hacer una contra zanja que condujera el agua hacia los campos del Doxey y que sería costeada por todos aquellos a quienes beneficiase. De la misma manera, los trabajos de desazolve tendrían que efectuarse con la colaboración de todos los interesados ${ }^{56}$ (véase mapa 4).

La situación de Axacuba era muy distinta. No se encontraba inmediata a ningún río o arroyo, pero en cambio en sus inmediaciones brotaban varios manantiales de agua termal, ${ }^{57}$ a la vez que contaban con innumerables jagüeyes que recogían el agua de lluvia de los cerros cercanos. Era un pueblo fundamentalmente dedicado a la cría de ovejas, bueyes y asnos; y, aunque tenían suficiente agua para darles de beber, no contaban con los pastos necesarios para su alimentación. Por ello, los indios pactaron con los dueños de la hacienda Tenguendó, para que éstos les permitieran introducir sus ganados en su tierras y cortar leña de sus bosques - hoy extintos- mientras que aquéllos darían agua a los animales de la hacienda. Las aguas de los "baños azufrosos" nacían en las inmediaciones de la iglesia del pueblo y eran almacenadas en "estanques" de mampostería. Con ellas se regaba maíz y trigo. ${ }^{58}$

\section{El valle de Tula}

En 1792, Tula contaba con aproximadamente 17 mil habitantes en nueve pueblos, 11 haciendas y 12 rancherías. La población no india ascendía a $23.9 \%$; de la cual, $11.7 \%$ eran espańoles, $4.6 \%$ castizos, $6.2 \%$ mestizos y $1.3 \%$ pardos, por lo que probablemente la población indígena era de $76 \%$. Un padrón fechado en 1794, que recoge datos de población del ańo anterior, indica que había 11,938 indios, de los que tan sólo 12.4 \% eran tributarios; a la vez que exis-

\footnotetext{
$21 \mathrm{v}-22 \mathrm{r}$. exp. 88 , f. 1 r.

${ }^{58}$ AGN, Tierras, vol. 2861, exp. 9, fs. 1r-8r.
}

56 "Acta del ayuntamiento de Atitalaquia (1823)", AGN, Tierras, vol. 3616, exp. 4, f.

57 "Carta de Ignacio Amezcua al padre Martín Montejano de su visita a la hacienda de Santa Lucia y a los baños de Axacuba (1761)”, AGN, Indiferente Virreinal, caja 5232, 
tían $18.5 \%$ españoles y $9.8 \%$ castizos. La población total era de 16,668 habitantes. ${ }^{59}$

Tula se ubica en la confluencia de los ríos Tula, Tlautla y Rosas, lo que le aportaba considerables beneficios a la agricultura, pero igualmente la sujetaba a frecuentes inundaciones en tiempos de lluvias:

Tula [...] está situado en un confluente que forman el río Grande [el Tula], que corre de Sur a Norte, y otro río que llaman Chico [el Rosas] que corre de Oeste a Este; lo que es causa de algunas inundaciones que suelen sobrevenir y entonces llega el agua hasta las casas reales, pero al par de esto disfrutan sus habitantes de un clima muy benigno y saludable. ${ }^{60}$

Uno de sus sujetos, Tepeji, es descrito en las fuentes de finales del virreinato como un lugar con clima templado, "muy agradable para la fertilidad de sus campos y cañada llena de huertas y frutas ricas de todas especies". ${ }^{61}$ En 1789, Antonio Alcedo describía la jurisdicción como: "muy fértil y abundante en frutos, de que abastece a México" ${ }^{62}$ Según los peritos, era cuantioso el volumen de agua del río Tula, a su paso se alimentaba de gran cantidad de arroyos y manantiales: "trae dicho río agua tan abundante que es lástima no haya otras muchas haciendas". ${ }^{63}$ El problema era que el territorio estaba completamente ocupado por pueblos, haciendas y el condado Moctezuma, ${ }^{64}$ por lo que al pedir una merced de agua se tenía necesariamente que pactar con los dueños río abajo o los pueblos vecinos por donde pasarían las nuevas zanjas, o con quienes perjudicaría la construcción de una nueva presa o molino.

59 "Padrón de la jurisdicción de Tula (1792)", AGN, Padrones, vol. 7, f. 297r; "Padrón levantado en la jurisdicción de Tula del distrito de la provincia de México (1794)", AGN, Indiferente Virreinal, caja 5251, exp. 20, 3 fs.

60 "Padrón de la jurisdicción de Tula (1792)", op. cit., f. 297r.

${ }^{61}$ Ibidem, f. 297r-297v.

${ }^{62}$ Antonio Alcedo, Diccionario geográfico-histórico de las Indias Occidentales, tomo IV, Madrid, Imprenta de Manuel González, 1789, 242.

${ }^{63}$ AGN, Mercedes, 1685, vol. 60, fs. 128 r.

${ }^{64}$ Para un estudio del condado Moctezuma véase: Verenice Cipatli Ramírez Calva, Caciques y cacicazgos indígenas en la región de Tollan, siglos XIV-XVII, Colección Investigaciones, Zamora, El Colegio de Michoacán, 2010. 
Gracias a las fuentes históricas ubicamos algunos de los sistemas de riego de la región. Los documentos consultados son escritos producto de litigios entre pueblos y haciendas, pero igualmente estudiamos mapas de la época a modo de ubicar la localización de las obras. En muchos casos, la reconstrucción de los sistemas de riego, que plasmamos en los mapas adjuntos, se logró únicamente con base en descripciones; en esos casos no contamos con localizaciones exactas. De esa manera nos acercaremos al sistema de riego de la hacienda Caltengo, al de Buenavista, Molino de Jaso, todas ellas dependientes del río Tepeji; igualmente contamos con información acerca del extenso sistema que involucraba a los pueblos de San Andrés, Xuchitlán, la hacienda de San Agustín Buenavista, la de San Antonio y el pueblo de Tula, que regaban sus campos derivando canales del río Rosas. Más al norte estaba la red de canales y presas de las haciendas San Pedro Mártir Nextlalpan y Endó, al igual que la del pueblo de Tepetitlán. Cuando vaciamos la información sobre riego en mapas actuales resultó sorprendente que muchos de esos antiguos sistemas de riego, que narran los documentos o plasman los mapas coloniales, los podemos continuar observando en cartas topográficas de la región.

Uno de los sistemas de riego más extensos de la región es el que involucra a la zanja Romera o Correo Mayor. Se originaba en una represa formada sobre el río Tepeji, en las inmediaciones del pueblo del mismo nombre. La presa derivaba el agua a un canal de cerca de nueve leguas de largo, con tramos subterráneos y acueductos con arcos. Cuando en 1759 don Bernardo Pérez de las Cuevas, notario del Santo Oficio, manifestó los títulos de tierras y aguas pertenecientes a su hacienda de San Miguel Chingú, indicó que en el año de 1742 se le habían mercedado veinticuatro surcos de agua del río Tepeji; dos años después construyó una zanja y acueductos con arcos de nueve leguas de largo que llegaban hasta su hacienda para conducir el preciado líquido $^{65}$ (véase mapa 5). Sobre él se construyó el canal Requena en el siglo $\mathrm{xX}$, que bien podemos observar en cartas topográficas.

65 "Manifestación de los títulos de la hacienda Chingú, de Bernardo Pérez de las Cuevas (1759)”, AGN, Tierras, vol. 2589, exp. 6, f. 4v; AGN, Tierras, vol. 2336, exp. 2, f. 21v. 
Mapa 5. Sistemas de riego de Tula

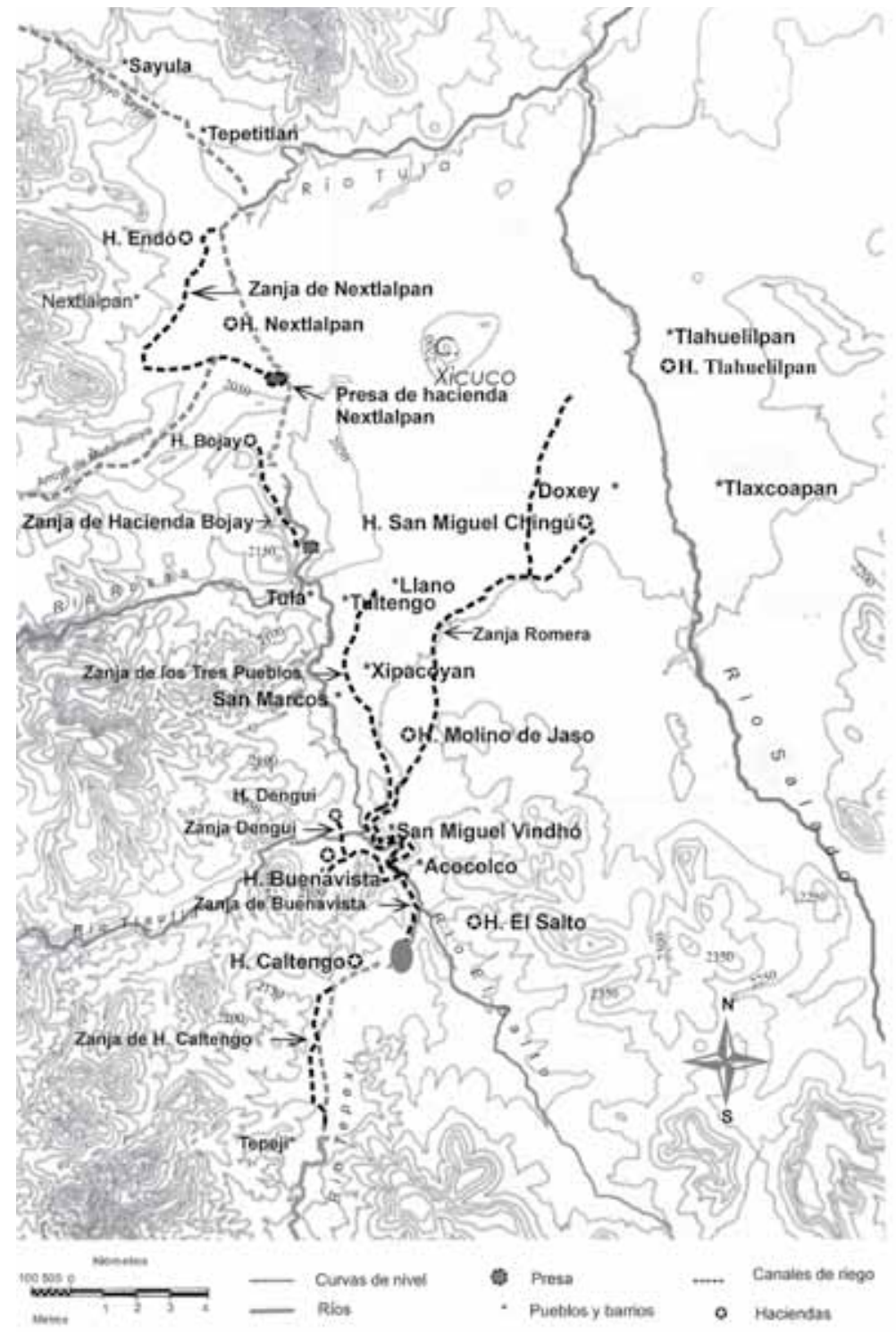

Fuente: INEGI. Cartas topográficas: Tula F14C88, Mixquiahuala F14C89, Tepexi E14A18, Zumpango E14A19. 
Posteriormente, tenemos el sistema de la hacienda Buenavista y su anexo Santa Efigenia Denguí. En un mandamiento virreinal fechado en 1743 se señala que ese mismo ańo se mercedó a Bernardo Pérez de las Cuevas 24 surcos de agua del río Tepeji, que conduciría hasta su hacienda de Santa Efigenia a través de la tarjea que había fabricado para la de Buenavista. Rastreando nueva información al respecto, supimos que años antes, en 1723 se le había mercedado a Buenavista la misma cantidad de agua, cuando entonces pertenecía a don Juan Gómez de Cervantes, Jasso y Ossorio. Y para 1739, ya habían hecho "arcos" y "acueductos" para conducir el líquido desde Buenavista hasta Santa Efigenia. ${ }^{66}$ Buenavista se encontraba muy próxima a la confluencia de los ríos Tlautla y El Salto. Ese canal probablemente es el llamado Denguí y el acueducto del mismo nombre, sólo que estos parten del Tlautla (véase mapa 4).

Otro sistema era el de la hacienda Caltengo, al sur de Buenavista. En 1685 se mercedaron seis surcos de agua del río Tepeji a Cristóbal Mascareñas Saravia; por medio de zanjas pudo llegar el líquido hacia sus sembradíos. Cercano al barrio de San Marcos se encontraba el Molino de Jaso, que igualmente tomaba agua del río Tepeji con ayuda de una zanja. La merced original data de 1552 , y fue hecha a Juan de Jaso "El Mozo"; es una de las más antiguas de la región. Es posible que se trate de la conocida zanja de los Tres Pueblos, que se prolonga hasta el barrio de Tultengo, en las inmediaciones de Tula, justo en tierras de la hacienda. Muy próxima a la zona arqueológica de Tula había sido puesto un dique donde nacía el canal que bañaba los campos de la hacienda Bojay, al igual que su molino. ${ }^{67}$ Actualmente, esos terrenos se encuentran bajo la presa Endó (véase mapa 5).

A pocos kilómetros de distancia con rumbo al norte estaba el sistema de la hacienda San Pedro Mártir Nextlalpan, que ya existía para $1723 .{ }^{68} \mathrm{La}$ zanja principal nacía en las cercanías del pueblo de Nex-

\footnotetext{
${ }^{66}$ AGN, Mercedes, vol. 75, f. 2v-3r; AGN, Mercedes, vol. 71, f. 272v-274r; AGN, Mercedes, vol. 73, f. 197r-197v.

${ }^{67}$ AGN, Mercedes, vol. 60, f. 128r-129v; AGN, Mercedes, vol. 73, f. 84v-86r y fs. 95v98r, Peter Gerhard, Sintesis e indice de los mandamientos virreinales, 1548-1553, México, UNAM, Instituto de Investigaciones Históricas, 1992, 200.

${ }^{68}$ AGN, Mercedes, vol. 71 , f. $272 \mathrm{v}-274 \mathrm{r}$.
} 
tlalpan, se alimentaba del río Tula y corría paralela a él y a pocos metros de su nacimiento formaba un presa. Ésta era de mampostería, con compuertas de morillo; tenía tres varas de alto, 40 de largo y los cimientos cuatro varas. Delante de la presa, la zanja viraba hacia el sureste, rodeando las tierras de labor de la hacienda, junto a los cerros, hasta encontrar el agua del arroyo de Michimaloya, para salir nuevamente en dirección noreste. Al parecer, el agua fue mercedada a la hacienda en 1643. En 1776, los peritos consideraban que la presa llevaba 60 surcos, pero que en tiempo de estiaje podían disminuir hasta 36. Antes de ese año, los remanentes se conducían nuevamente a la madre del río, pero a partir de entonces el canal se prolongó para beneficiar también a la hacienda Endó, entonces propiedad de Felipe Antonio Turuel, descendiente de los condes de Moctezuma. Todavía para 1820 el sistema continuaba en uso ${ }^{69}$ (véase mapa 5).

Endó igualmente tenía otras fuentes de agua. Un canal se originaba en el arroyo de Sayula; ahí donde éste desemboca, en el río Tula, se había colocado una presa, que por medio de una zanja de cal y canto de varios kilómetros, que en partes iba tapado y en otras descubierto, las aguas descendían hasta Endó, regando a su paso las tierras del pueblo de Tepetitlán. Las mercedes de agua a la hacienda datan de 1719, cuando don Gabriel Guerrero Ardila -contador del Tribunal de Cuentas de la Nueva España-, y entonces poseedor de la hacienda, recibió una merced que le permitió represar el agua del arroyo de Sayula y del río Tula. ${ }^{70}$ No obstante, desde el siglo xvi los indios de Tepetitlán, al igual que los de Sayula, se beneficiaban de las mismas fuentes. En el primer pueblo referido habían construido una zanja que pasaba por el centro del pueblo y de ella satisfacían no sólo sus necesidades domésticas sino también agrícolas. ${ }^{71}$ A la muerte de Guerrero Ardila quedó como su albacea Juan Francisco de Orduña, Sosa y Castilla, familiar de la Inquisición. ${ }^{72}$ En 1736 , Orduña intentó

69 "Diligencias promovidas por don Vicente Ximenez sobre amparo (1820)", AGN, Tierras, vol. 3570, exp. 3, fs. 1r-44r.

${ }^{70}$ AGN, Mercedes, vol. 71, fs. 113r-113v; AGN, Mercedes, vol. 76, f. 151-155v; AGN, Tierras, vol. 2587, exp. 1, 60 fs.; AGN, Tierras, vol. 776, exp. 1, 122 fs.; AGN, Tierras, vol. 3570, exp. 3, fs. 1-56v.

${ }^{71}$ Francisco del Paso y Troncoso, op. cit., p. 226.

${ }^{72}$ AGN, Indiferente Virreinal, caja 3839, exp. 6, 4fs; AGN, Inquisición, vol. 375, exp. 7. 
modificar el curso de la antigua zanja, que recorría varios kilómetros hacia el sur y en su curso hacia la hacienda de Endó pasaba a poca distancia del convento franciscano de Tepetitlán; mas sus pretensiones fueron obstaculizadas por Sayula. ${ }^{73}$ Apenas cuatro años después, la zanja estaba tapada y únicamente beneficiaba a la hacienda. Pero en 1747 la Audiencia determinó que en adelante los indios gozarían tres días de agua; mientras Baltasar de Vidaurre, entonces poseedor de la hacienda Tepetitlán, la utilizaría los días restantes de la sema$\mathrm{na}^{74}$ (véase mapa 5).

Pasemos ahora al río Rosas. El pueblo de Tula y los religiosos del convento franciscano se abastecían del agua del río Rosas, que nacía en los ojos de agua del sitio conocido como Mexicaltongo, en las inmediaciones del pueblo de San Agustín. A lo largo de su recorrido se nutría con infinidad de arroyos que en tiempos de lluvias descendían de las barrancas cercanas. De ese río se aprovechaban los pueblos de San Agustín, Xuchitlán, San Andrés y Tula, incluso las haciendas de San Agustín Buenavista y San Antonio. Semejante al caso de Tepetitlán, ya desde el siglo xvi, Tula y Xuchitlan habían construido canales y zanjas de esa fuente. ${ }^{75}$

En 1697, todos los interesados en el uso del sistema de riego hicieron un convenio donde se establecían las reglas para el uso del agua, así como la forma en que se había de conducir desde el nacimiento del río Rosas a las haciendas y de ahí al pueblo. El convenio estableció que la hacienda de San Antonio podía gozar de las aguas de los ojos de Mexicaltongo sólo si se comprometía a dejar fluir los remanentes al río Rosas para que luego los tomara el pueblo de Tula. A fin de evitar escasez, ninguna de las dos haciendas podía abrir más tierras de labor. San Antonio podía llevar el agua hacia sus tierras

${ }^{73}$ AGN, Tierras, vol. 776, exp. 1, f. $14 \mathrm{r}$.

${ }^{74}$ AGN, Mercedes, vol. 76, fs. 151v-154r; Francisco Luis Jiménez Abollado y Verenice Cipatli Ramírez Calva, "Conflictos por el agua en Tepetitlán (Hidalgo, México), siglo xviII", Fronteras de la historia, vol. 16-1, enero-junio, 2011, 209-238.

${ }^{75}$ AGN, Tierras, vol. 2719, exp. 10, f. 9r; AGN, Mercedes, vol. 73, fs. 97r; Francisco del Paso y Troncoso, op. cit., pp. 194 y 289; Verenice Cipatli Ramírez Calva, "Indios y españoles en la contienda por el control del agua en Tula, Hidalgo, siglos XVIII-XIX", Dimensión Antropológica, México, INAH, año 16, vol. 47, septiembre-diciembre, 2009, 103 124. 


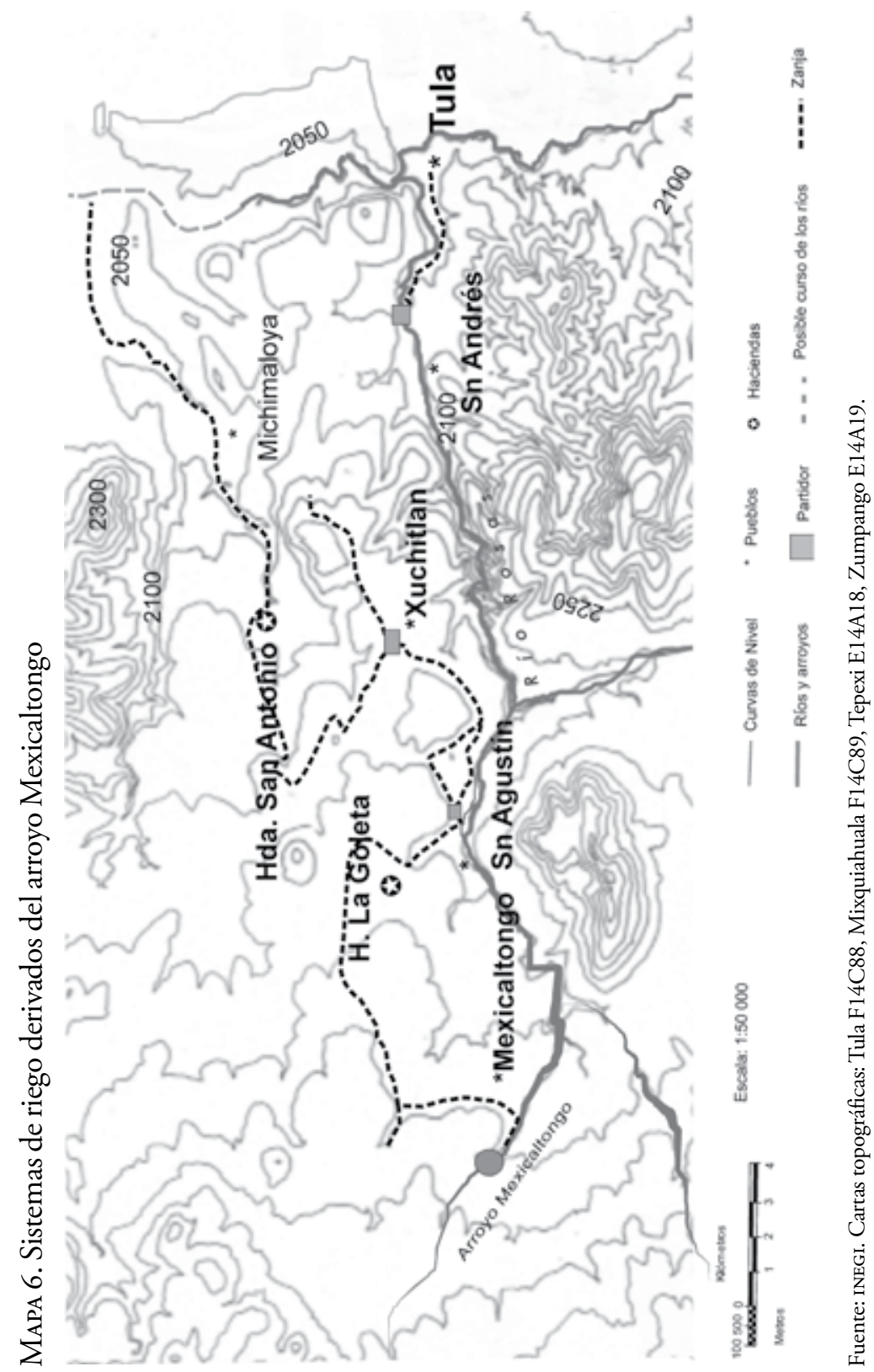


desde la toma localizada a espaldas de la iglesia de San Agustín. Mientras que el pueblo de Tula se obligaba a construir presa de cal y canto cercana a otra que tenía sobre el río Rosas. ${ }^{76}$ En los años subsecuentes las dos haciendas se dieron a la tarea de construir una red de canales, presas y partidores, con miras a aumentar los terrenos destinados al cultivo de trigo.

A mediados del siglo xviII, el sistema de riego estaba constituido por una presa en el nacimiento del río Rosas (arroyo de Mexicaltongo), de ahí partía una zanja que conducía el agua por tierras de La Goleta, hacia el norte, pasando por detrás de la hacienda, volviendo luego hacia el sur hasta llegar al pueblo de San Agustín donde había otro partidor que conducía el agua tanto a San Antonio como al pueblo de San Agustín. Del partidor de Xuchitlán salía una zanja que llevaba el agua a la hacienda San Antonio y ésta derramaba los remanentes en las barrancas de Michimaloya, al norte de Tula, dejando caer el agua en el río Tula, a varios kilómetros del pueblo, río abajo. En la parte oeste de Tula, en las cercanías del pueblo de San Andrés, había una presa y de ella nacía la acequia principal que al llegar al pueblo se bifurcaba en ramales, uno de ellos desembocaba en el interior del mismo convento y otro en el molino de trigo de la comunidad. A pesar de lo problemático que resultó mantener de manera relativamente pacífica la vida de este sistema, aún lo encontramos vigente hacia $1808^{77}$ (véase mapa 6).

\section{Consideraciones finales}

La falta de agua en regiones con escasas de lluvias, pero con ríos, arroyos y manantiales cercanos, llevó a sus habitantes a idear las formas y vías para acceder al vital líquido. Esos son los casos de Tula, Ixmiquilpan y Tetepango. Acceder al agua no era una tarea fácil ni para hacendados ni para los pueblos de indios. Siempre que una nueva presa, canal o molino era construido las quejas y suspicacias

${ }^{76}$ AGN, Mercedes, vol. 73, fs. $47 \mathrm{v}-50 \mathrm{r}$.

${ }^{77}$ AGN, Mercedes, vol. 73, fs. 12r-19v, 24r-31r y 61v-62r, AGN, Tierras, vol. 1669, exp. 4, 56 fs. 
de los asentados río abajo afloraban. Por lo que siempre era necesario pactar. En los pocos acuerdos que han llegado a nuestros días, se indican las horas y días que cada uno debía gozar el agua; así como las obligaciones relativas al mantenimiento de la infraestructura hidráulica o su ampliación. Sin embargo, no tenemos información sobre el tema para todos los casos descritos. Pero cuando los convenios se violaban los conflictos estallaban, en algunos casos de manera violenta, en otros se presentaron con menos intensidad; entonces los usuarios afectados presentaban las mercedes que los amparaban de "inmemorial tiempo" o bien mostraban los escritos donde constaba el uso mutuo del agua y la infraestructura. El mantenimiento y remodelación de sistemas hidráulicos fue otro factor necesario para el mayor aprovechamiento posible de las aguas disponibles, ya fuera que proviniesen de ríos, arroyos o jagüeyes; e igualmente fue objeto de litigios. En algunos casos, como en el de los pueblos de Atitalaquia, Tlahuelilpan y Tlaxcopan, la construcción de presas o canales de irrigación se efectuó bajo la mutua ayuda de pueblos y hacendados; mas no por ello los conflictos dejaron de estar ausentes, sobre todo cuando los años solían ser particularmente secos. En otros, las zanjas y jagüeyes fueron planeados, controlados y administrados únicamente al interior de los pueblos de indios, entre sus tributarios, como en Maguey Blanco.

Finalmente cabe señalar que gran parte de los canales y presas, de que hemos hecho mención, fueron reutilizados y ampliados al tiempo de la construcción del distrito de riego 03. Queda pendiente la tarea de profundizar en las características del riego durante todo el siglo XIX e indudablemente los cambios generados en el siglo Xx, especialmente en la primera mitad.

\section{Archivos consultados}

AGEH, Archivo General del Estado de Hidalgo. AGN, Archivo General de la Nación, México. cDBmnah, Centro de Documentación de la Biblioteca del Museo Nacional de Antropología e Historia 
BibLIOGRAFÍA

Acuña, René, ed., Relaciones geográficas del siglo XV, tomo III, México, UNAM-Instituto de Investigaciones Antropológicas, 1986.

AlCEDo, Antonio, Diccionario geográfico-histórico de las Indias Occidentales, tomos IV y v, Madrid, Imprenta de Manuel González, 1789.

Cobean, Robert y Alba Guadalupe Mastache, "The late Classic and the Early Postclassic Chronology of the Tula Region" en Dan Healan, ed., The Tula of the Toltecs. Excavations and Survey, Iowa, University of Iowa Press, 1989, 34-46.

Echenique March, Felipe I. y Lourdes M. Romero Navarrete, Relaciones geográficas de 1791, México, INAH, 1994.

García Acosta, Virginia, Juan Manuel Pérez Zevallos y América Molina del Villar, Desastres agrícolas en México. Catálogo Histórico. Tomo I, Épocas prehispánica y colonial (958-1822), México, Fondo de Cultura Económica, Ciesas, 2003.

Gerhard, Peter, Geografia Histórica de la Nueva España, 15191821, México, UNAM, 2000.

, Sintesis e indice de los mandamientos virreinales, 1548-

1553, México, unam, Instituto de Investigaciones Históricas, 1992. Grijalva, Juan de, Crónica de la orden de N.P.S. Agustín en las provincias de la Nueva España, en cuatro edades desde el año de 1533 hasta el de 1592, México, Porrúa, 1985.

Jiménez Abollado, Francisco Luis y Verenice Cipatli Ramírez Calva, "Conflictos por el agua en Tepetitlán (Hidalgo, México), siglo xviII", Fronteras de la Historia, vol. 16-1, enero-junio, 2011, 209-238.

Maderey, Laura Elena, "El recurso agua en la República Mexicana. Un breve análisis geográfico", Revista Geográfica, Pan American Institute of Geography and History, núm. 119, enero-junio, 1994, 133-163.

Mastache, Alba Guadalupe, "Sistemas de riego en el área de Tula, Hgo." en Eduardo Matos Moctezuma, coord., Proyecto Tula. Segunda parte, Colección Científica, 33, México, INAH, 1976, 49-70. MelVille, Elionor, A plague of sheep. Environmental consequences of 
the Conquest of Mexico, Melbourne, Cambridge University Press, 1994.

Paso y Troncoso, Francisco del, Papeles de la Nueva España. Geografía y estadistica. Tomo I, Suma de visitas de pueblos por orden alfabético, Madrid, Sucesores de Rivadeneyra, Imprenta de la Real Casa, 1905.

Ramírez Calva, Verenice Cipatli, "El agua, los pueblos de indios y las haciendas. Tetepango, siglos XVIII-XIX" en Daniel Murillo y Jacinta Palerm, eds., Memorias del Primer Congreso de la red de Investigadores Sociales sobre el Agua, Jiutepec, México, IMTA, http://redissa.hostei.com/rissa/Ramirez_Verenice.pdf

, "El comercio en las jurisdicciones de Ixmiquilpan, Actopan y Tetepango-Hueypuchtla, siglos XVIII-XIX". Ponencia presentada en el seminario "El comercio y las participaciones indígenas en el siglo xvıII", Zamora, El Colegio de Michoacán, 15-16 mayo, 2008.

, Caciques y cacicazgos indígenas en la región de Tollan, siglos XIV Y XVII, Colec. Investigaciones, Zamora, El Colegio de Michoacán, 2010.

, "Indios y españoles en la contienda por el control del agua. Tula, siglos XVIII-XIX”, Dimensión Antropológica, ańo 16, vol. 47, septiembre-diciembre 2009, 103-124.

, "Itzmiquilpan: un paisaje en construcción. Procesos de reconformación regional, siglos XVI y XVII", tesis de maestría, Zamora, Centro de Estudios Antropológicos, El Colegio de Michoacán, 2001.

Solano, Francisco de, ed., Relaciones geográficas del Arzobispado de México, 1743, tomo I, Madrid, Consejo Superior de Investigaciones Científicas-Centro de Estudios Históricos, Departamento de Historia de América, 1998.

Villaseñor y Sánchez, Antonio, Teatro americano, descripción general de los reinos y provincias de la Nueva España y sus jurisdicciones, México, Editora Nacional, 1951-1952.

FECHA DE RECEPCIÓN DEL ARTÍ́Culo: 22 de julio de 2011

FECHA DE RECEPCIÓN DE LA VERSIÓN FINAL: 28 de enero de 2012 